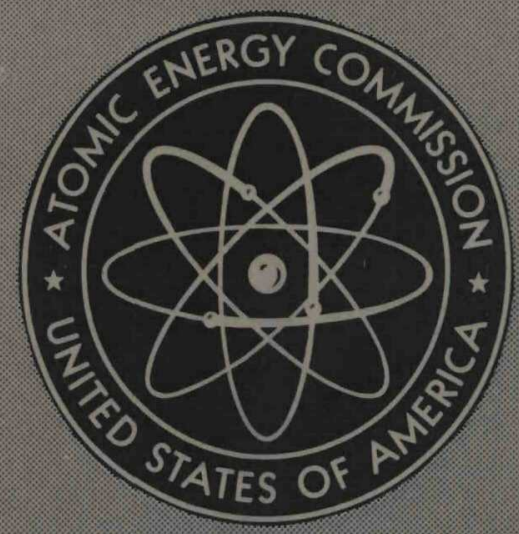

MND-P-2369

PHYSICS AND MATHEMATICS

\title{
CONCEPTUAL DESIGN OF A SNAP III TYPE GENERATOR FUELED WITH CERIUM-144
}

By

Robert J. Wilson

June 1960

Nuclear Division

Martin Company

Baltimore, Maryland 


\section{DISCLAIMER}

This report was prepared as an account of work sponsored by an agency of the United States Government. Neither the United States Government nor any agency Thereof, nor any of their employees, makes any warranty, express or implied, or assumes any legal liability or responsibility for the accuracy, completeness, or usefulness of any information, apparatus, product, or process disclosed, or represents that its use would not infringe privately owned rights. Reference herein to any specific commercial product, process, or service by trade name, trademark, manufacturer, or otherwise does not necessarily constitute or imply its endorsement, recommendation, or favoring by the United States Government or any agency thereof. The views and opinions of authors expressed herein do not necessarily state or reflect those of the United States Government or any agency thereof. 


\section{DISCLAIMER}

Portions of this document may be illegible in electronic image products. Images are produced from the best available original document. 


\section{LEGAL NOTICE}

This report was prepared as an account of Government sponsored work. Neither the United States, nor the Commission, nor any person acting on behalf of the Commission:

A. Makes any warranty or representation, expressed or implied, with respect to the accuracy, completeness, or usefulness of the information contained in this report, or that the use of any information, apparatus, method, or process disclosed in this report may not infringe privately owned rights; or

B. Assumes any liabilities with respect to the use of, or for damages resulting from the use of any information, apparatus, method, or process disclosed in this report.

As used in the above, "person acting on behalf of the Commission" includes any employee or contractor of the Commission, or employee of such contractor, to the extent that such employee or contractor of the Commission, or employee of such contractor prepares, disseminates, or provides access to, any information pursuant to his employment or contract with the Commission, or his employment with such contractor.

This report has been reproduced directly from the best available copy.

Printed in USA. Price $\$ 1.25$. Available from the Office of Technical Services, Department of Commerce, Washington 25, D. C. 


$$
\text { MND-P-2369 }
$$

CONCEPTUAL DESIGN OF A SNAP III

TYPE GENERA TOR FUELED WITH CERIUM-144

Prepared by:

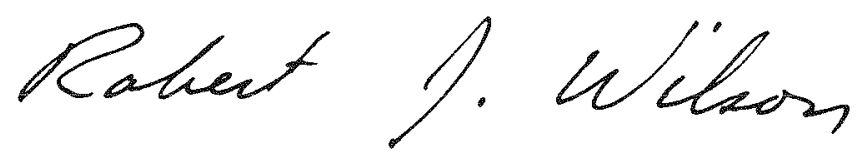

Asst. Project Engineer

June 1960

Nuclear Division

Martin Company

Baltimore, Maryland 
Blank 


\section{FOREWORD}

This report was prepared by The Martin Company in fulfillment of Task 5. Subtask 5.5, under Contract A T(30-3)-217 with the U.S. Atomic Energy Commission. It covers a portion of the work performed under this subtask during the period July 1, 1959, through June 30, 1960. 
Blank

Blank

Blank

Blank

Blank

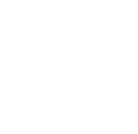

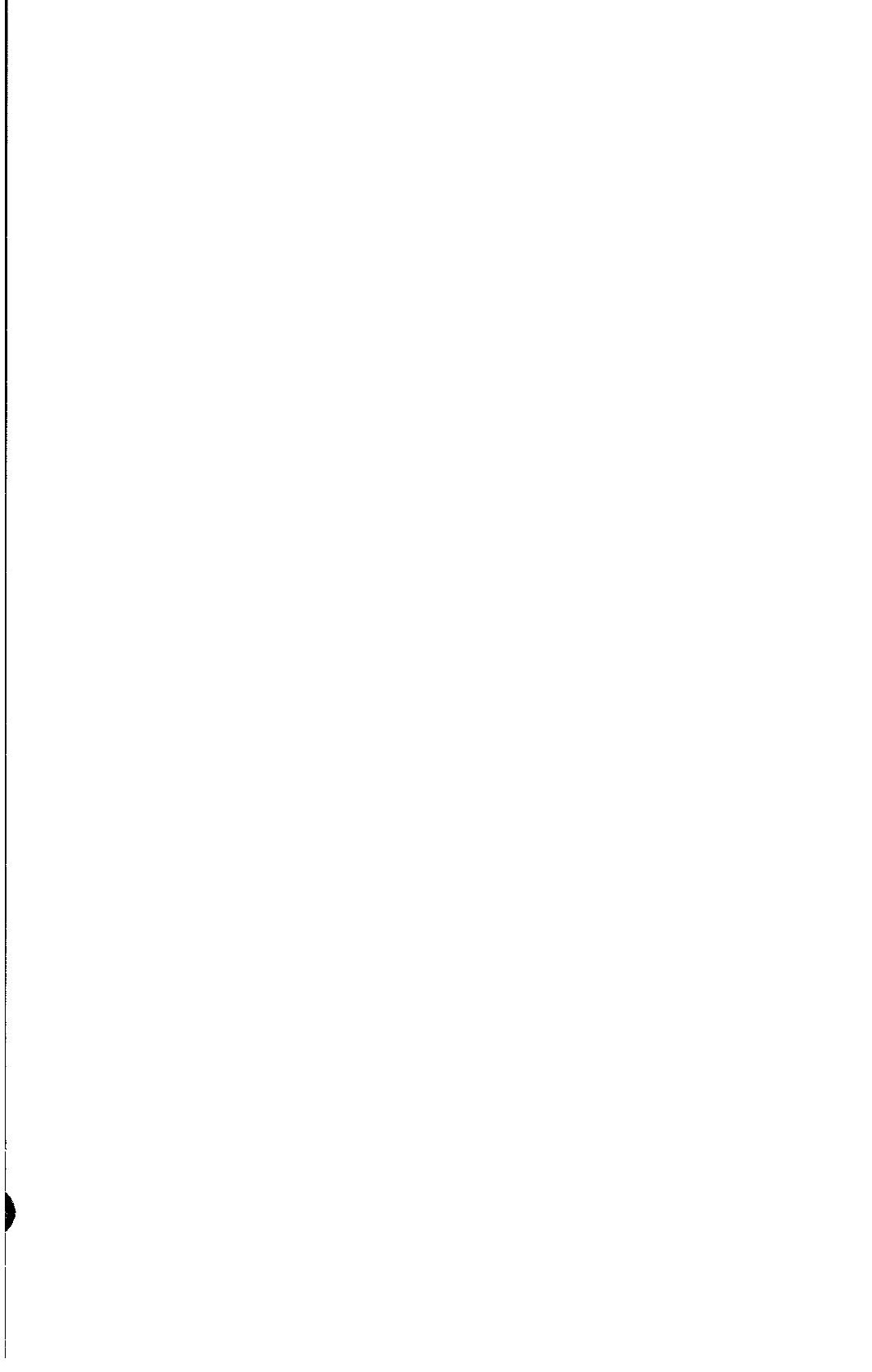




\section{CONTENTS}

Page

Foreword .......................... v

Contents ............................ vii

Summary........................... $1 x$

I. Introduction ................... 1

II. Generator Configuration . . . . . . . . . . . 3

A. Fuel ..................... 3

B. Capsule ....................... 6

C. Thermal Converter ............... 14

D. Mercury Shield Container ............ 17

E. Lead Shield Concept ............... . 19

III. Generator Installation . . . . . . . . . . . . . . 21

A. Mercury Shield Concept ............. 21

B. Lead Cask Shleld Concept . . . . . . . . . . 21

C. Dose Rates and Working Times .......... 23

IV. Generator Performance .............. 27

A. Sphere Temperature Determination .......... 27

B. Generator Output ................... 28

V. Ground Handling Procedures ... . . . . . . . . 33 
A. Fuel Processing Facility ............... 33

B. Martin Nuclear Facility .............. 35

C. Launch Site . . . . . . . . . . . . . 35

VI. Conclusions . . . . . . . . . . . . . . . . . 43

VII. References...................... 45

Appendix--Summary of Generator Performance Test Results . A-1 
This report presents a design concept for an electrical system using two SNAP III-type generators fueled with cerium.

Developments by The Martin Company in connection with the SNAP IA program provided a fuel form consisting of cerium oxide with an additive of silicon carbide. In the modified SNAP III generator, a capsule of Haynes 25 contains 9725 curies of cerium oxide pellets, which will provide 67 thermal watts at time of launch. Sufficient void volume and capsule strength ensure containment of the oxygen evolved through isotope decay during the operational life of the generator.

Thermal converter configuration in the conceptual generator is identical to that of the SNAP III except that the shell is stainless steel.

Two methods of biological shielding are considered. The first uses mercury contained in a sphere surrounding the generator. In the second concept, a lead cask shields the unit until its installation in the launch vehicle. A remote installation procedure and an equipment arrangement are proposed.

Generator output predictions were based on actual test data. The output of a single unit would be 3.8 watts at launch, decreasing to 1.9 watts in the course of a 6-month mission. A ground handling procedure and conceptual designs of the equipment are included. 


\section{INTRODUCTION}

The Martin Company received a joint request from the Aircraft Reactors Branch of the Atomic Energy Commission and Air Force Ballistic Missile Division for the investigation of a SNAP III-type generator fueled with cerium, early in Fiscal Year 1960. This request was subsequently incorporated as a portion of the Task 5, Subtask 5.5 program plan (Ref.1) and statement of work (Ref.2)。

The objective of this portion of the program was the development of a conceptual system design based on the results of operational tests also conducted under this subtask. Power requirements of 3 to 5 watts for a 6-month mission were established. Minimum modification of the SNAP III generator would allow direct application of results of concurrent testing. Since a similar launching vehicle was proposed, this system would also serve as a prototype of the SNAP IA system. 
Blank 


\section{GENERATOR CONFIGURATION}

One of the basic criteria of this program was to utilize the SNAP III generator with as little modification as possible; SNAP III has been thoroughly tested as to both safety and reliability。For ease in description, the generator system has been divided into four major components: radioisotope fuel, fuel capsule, thermal converter and shield container。A second design using lead rather than mercury as shield material was also investigated。

\section{A. RADIOSOTOPE FUEL}

Cerium-144 was the specified radioisotope fuel for this program. The basis for its selection was its availability: Cerium-144 is a fission product separated from reactor wastes at Oak Ridge National Laboratory. It has a half life of 285 days and decays through beta emission to Praseodymium-144, which in turn decays through beta emission with a half life of 17.5 minutes. The third element in the decay scheme, Neodymium144 , decays with a half life of $1.5 \times 10^{15}$ years through emission of an alpha particle. Because of its long half life, Neodymium-144 is considered to be stable. Although some of the thermal power originates from the Cerium-144 decay, the major energy source is the Praseodymium-144 decay, in which $98 \%$ of the beta particles have energies of $3.0 \mathrm{mev}$. The decay scheme, particle energies and radiation spectrum are discussed in more detail in Refs. 3 and 4 .

To avoid duplication of effort, the program plan (Ref. 1) and statement of work (Ref. 2) specified that the fuel form be provided through the development work performed under Task 2 for the SNAP IA generator.

\section{Fuel Form Development (Ref。5)}

Originally, the SNAP IA generator was fueled with Cerium-144 in the form of ceric oxide, $\mathrm{CeO}_{2}$, since this compound melts at a high temperature and is stable at high temperatures. However, re-entry location could not be surely predicted, and the SNAP Hazards Advisory Committee recommended that burnup through aerodynamic heating be used as the re-entry disposal method. Therefore, a fuel form that would disperse as small particles through oxidation, melting or vaporization was required. Additional necessary properties of the fuel form were reasonable cerium density and adaptability to hot-cell preparation. 
Of the many materials studied and tested, ceric oxide with silicon carbide as an additive was chosen. The silicon carbide additive was selected initially for its ability to reduce the oxide at elevated temperatures. However, because of the nature of the reaction products during ablation, considerable lowering of the melting or decomposition temperature was also noted. In all of the oxyacetylene torch tests used for screening purposes, only three additives--molybdenum, iron and $\mathrm{SiC}-\infty$ produced bodies with good densities and burnup qualities. These materials were further evaluated in the plasma flame generator, where the $10 \%$ $\mathrm{SiC}$ additive had the same burnup time as a $30 \%$ molybdenum additive. Silicon carbide however, gave the added advantage of a lower decomposition temperature.

2. Fuel Properties (Ref。3)

The ceric oxide is shaped into right cylindrical pellets by compacting under pressure and sintering at elevated temperature. These ceramic pellets, made at ORNL, contain $89 \% \mathrm{CeO}_{2}, 10 \% \mathrm{SiC}$ and $0.5 \% \mathrm{CaO}$ by weight. The properties of ceric oxide and the effects of adding silicon carbide are listed in Table 1. The apparent differences between the theoretical and predicted actual values are attributed to the impurities, additives and decay arising as a result of the fuel reclamation and fabrication process used at ORNL. The silicon carbide additive lowers the effective melting point or decomposition temperature to $1800^{\circ} \mathrm{C}$. Some $\mathrm{Ce}_{2} \mathrm{O}_{3}, \mathrm{CeC}_{2}$ and $\mathrm{CeSi}_{2}$ are formed at elevated temperatures.

Because of the difference in oxidation states between cerium and its decay products, oxygen is evolved within the fuel during decay. This oxygen is distributed evenly throughout the fuel pellets. The total mass accumulated at any time may be computed, but the computed value is meaningless by itself. Some oxygen is retained in the lattices of the fuel material and does not migrate to the surface of the pellet. In addition, the temperature and void volume of the capsule must be known before the capsule pressure caused by the accumulated oxygen may be computed. This is discussed in the next section of this chapter.

The quantity of fuel required in each generator unit is 9725 curies. According to the characteristics of the ORNL-produced ceric oxide with silicon carbide additive as given by Table 1 , the mass of fuel required is approximately 37 grams. Approximately 72 thermal watts of heat will be produced at time of capsule loading, which is assumed to be coincident with generator loading. These values are also based on an assumed 30day delay from capsule loading to generator launch in a satellite missile system. The fuel quantity depends on the thermal energy requirements developed in Chapter IV of this report. 
TABLE 1 (Ref. 3)

Properties of the $\mathrm{Ce}-144 \mathrm{O}_{2}$ and $\mathrm{CeO}_{2}-\mathrm{SiC}_{2}$ Fuel Forms

Chemical

Solubility in water

Concentrated $\mathrm{H}_{2} \mathrm{SO}_{4}, \mathrm{HNO}_{3}$

Dilute acid

Stability in air

Physical

Molecular weight

Color

Melting point $\left({ }^{\circ} \mathrm{C}\right)$

Boiling point $\left({ }^{\circ} \mathrm{C}\right)$

Theoretical density $(\mathrm{gm} / \mathrm{cc}$ )

Pellet bulk density ( $\mathrm{gm} / \mathrm{cc}$ )

Crystalline structure

Thermal

Thermal conductivity (cal $/ \mathrm{sec} / \mathrm{cm} /{ }^{\circ} \mathrm{C}$ )

Specific heat $\left(\mathrm{cal} / \mathrm{gm} /{ }^{\circ} \mathrm{C}\right)$

Thermal coefficient of expansion

$\left(\mathrm{cm} / \mathrm{cm} /{ }^{\circ} \mathrm{C}\right)$

Specific activity (curles/gm)

Theoretical

ORNL process

Specific power (watts/gm)

Theoretical

ORNL process

Power activity-oRNL (watt/curie)

Power density--ORNL process (watts/cc)
$\begin{array}{lc}{\mathrm{Ce}-144 \mathrm{O}_{2}}_{2} & \mathrm{Ce}-144 \mathrm{O}_{2}+10 \% \mathrm{SiC} \\ \text { Insoluble } & -- \\ \text { Soluble } & -- \\ \text { Insoluble } & -- \\ \text { Stable } & --\end{array}$

140.13

Yellow -

white

2600

3800

7.3

Grey-green

1800 *

5.6

6. 44

Face -

centered

cubic

0.01

0.1

$12.1 \times 10^{-6}$

$2.6 \times 10^{3}$

$2.34 \times 10^{3}$

295

265

19.2

17.3

2. 18

1.96

0.0074

0.0074

12.2

10.6

* Decomposes 


\section{B. FUEL CAPSULE}

SNAP III demonstration units delivered to the AEC had outer capsules of molybdenum. They were closed by a tapered stainless steel plug pressed into place after the polonium canister had been inserted. This closure method appeared inadequate in view of the environmental extremes possible in an operational application. Further, the use of a refractory metal was not compatible with the choice of aerodynamic burnup as the disposal method. Another fuel capsule material was chosen for the generator of this report, the selection based on the results of a study of published material data and conferences with personnel at Battelle Memorial Institute.

\section{Capsule Material Selection (Ref.6)}

The superalloy group of materials cannot compete with refractory metals in the high temperature regions but offer advantages for this application. Their melting points, from $2400^{\circ}$ to $2650^{\circ} \mathrm{F}$, increase fuel dispersion possibilities since the capsule would disintegrate with less heat input at higher altitudes. Their ultimate tensile strengths vary widely and decrease when the metals are aged at elevated temperatures. This decrease is illustrated in Fig. 1.

Resistance of these materials to impact loads is difficult to determine rigorously since the best laboratory test method, Charpy V-Notch, is difficult to reproduce and only compares one material to another. The best data available indicates that among several materials considered Haynes Alloy No. 25 provides the highest impact resistance. Figure 2 shows the Charpy impact strengths of several alloys.

As a result of this investigation, Haynes 25 was chosen as the material most likely to satisfy the radioisotope container criteria for this application. Although other superalloys offer superior ultimate tensile strengths, this advantage is offset by their lower impact resistances at the design operating temperature, $1100^{\circ} \mathrm{F}$. The pertinent data on Haynes 25 are listed in Table 2 and plotted in Fig. 3 (Ref. 7). Some discrepancy exists in the values of ultimate tensile strength at $1100^{\circ} \mathrm{F}$ between Figs. 1 and 3; the lower value, 90,000 psi, was used.

\section{Fuel Capsule Design}

The capsule design used in the original demonstration units was revised to take full advantage of the properties of Haynes 28 . Incorporation of a threaded plug was feasible since machining Haynes 25, though timeconsuming, is easier than machining molybdenum. Because Haynes 25 responds well to welding, that process was used to provide a pressure seal. 


\section{Ultimate Tensile Strength}

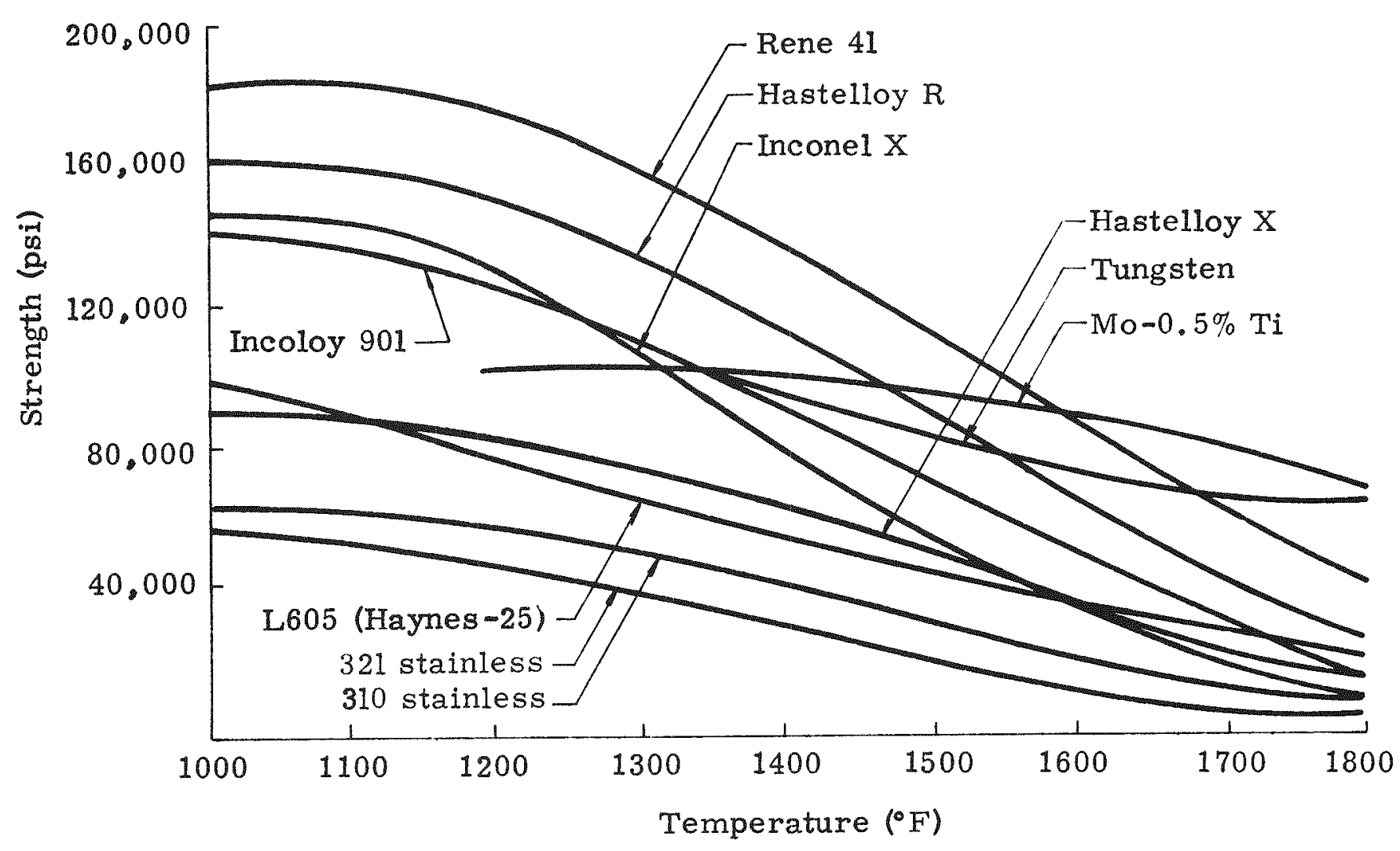




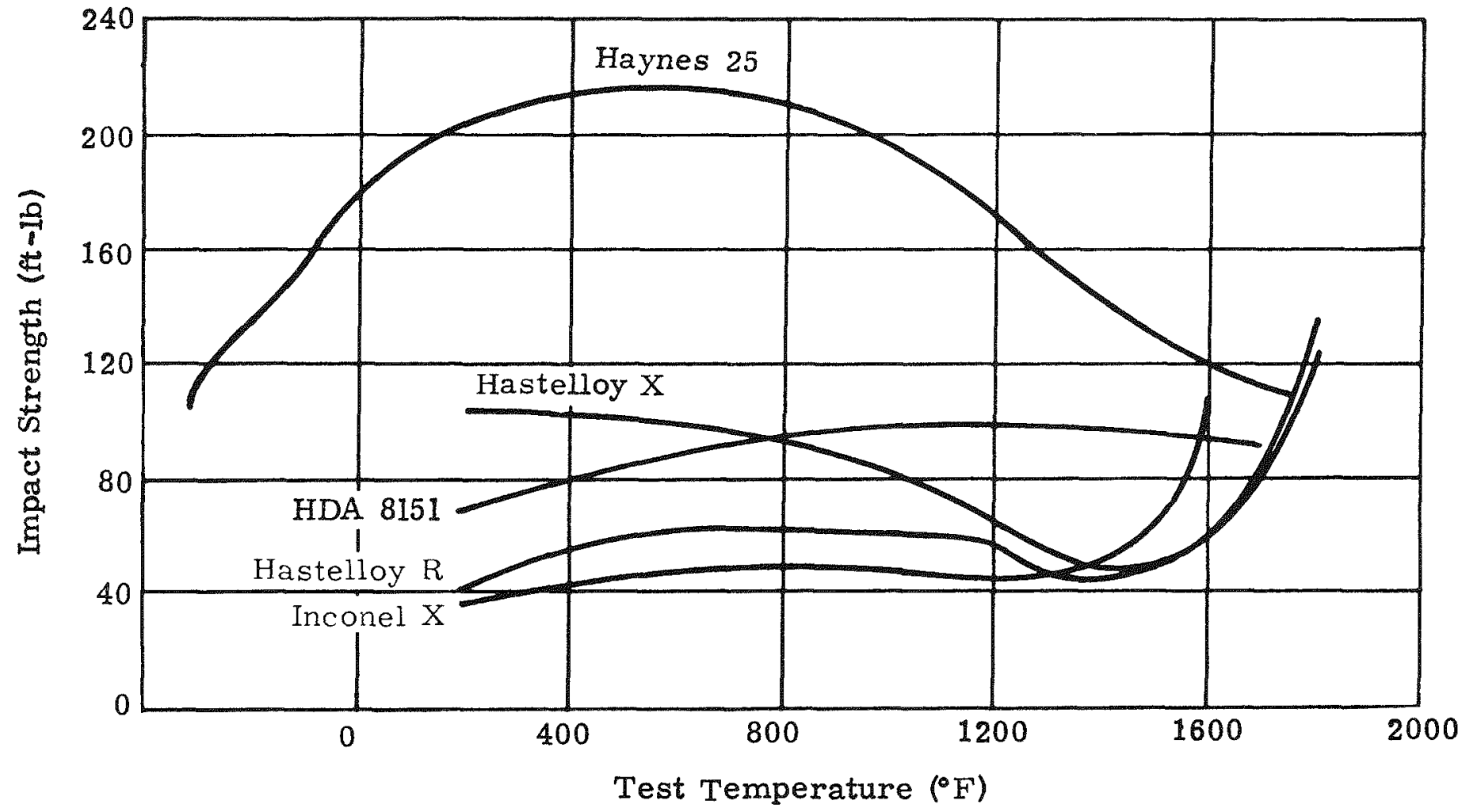

Fig. 2. Charpy Impact Strength Versus Temperature 
TABLE 2 (Ref. 7)

Chemical Composition and Physical Properties of Haynes 25

Chemical Composition

Constituent

Cobalt

Chromium

Tungsten

Nickel

Manganese

Carbon

Iron

Silicon
Weight $(\%)$

45.85 to 56.95

19.00 to 21.00

14.00 to 16.00

9.00 to 11.00

1.00 to 2.00

0.05 to 0.15

3.00 (maximum)

1.00 (maximum)

Physical Properties

Density

$0.330 \mathrm{lb} /$ in. $^{3}$

Melting range

$2425^{\circ}$ to $2570^{\circ} \mathrm{F}$

Thermal expansion $\left(70^{\circ}\right.$ to $\left.1200^{\circ} \mathrm{F}\right)$

8.24 microinch $/$ in. $-^{\circ} \mathrm{F}$

Thermal conductivity $\left(1100^{\circ} \mathrm{F}\right)$

142.2 Btu-in. $/ \mathrm{ft}^{2}-\mathrm{hr}-{ }^{\circ} \mathrm{F}$

Soecific heat $\left(80^{\circ}\right.$ to $\left.212^{\circ} \mathrm{F}\right)$

$0.092 \mathrm{Btu} / \mathrm{lb}-{ }^{\circ} \mathrm{F}$

Ultimate tensile strength (room temp)

$150,000 \mathrm{psi}$

Ultimate tensile strength $\left(1100^{\circ} \mathrm{F}\right)$

90,000 psi

Yield strength (2\% offset, room temp)

70,000 psi

Yield strength $\left(2 \%\right.$ offset, $\left.1100^{\circ} \mathrm{F}\right)$

50,000 psi 

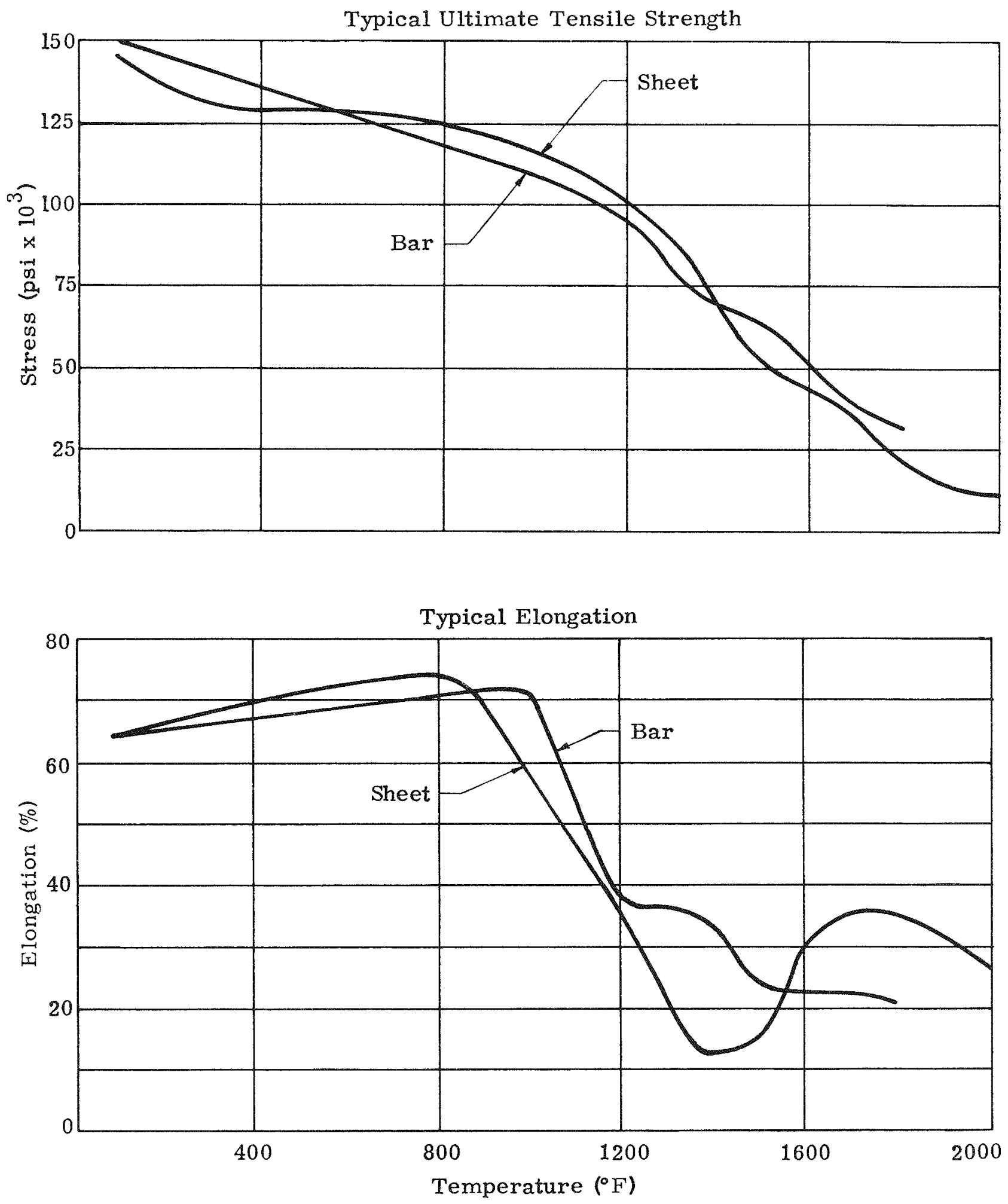

Fig. 3 Strength and Elongation of Haynes 25 as Functions of Temperature (Ref. 7) 
Capsule configuration is shown in Fig. 4. External diameters were held constant in the tapered section to obviate changes in the thermal converter portion of the generator. Internal cavity dimensions and overall length were increased to compensate for the lower specific power of the cerium fuel. This configuration provides a total volume of 0.444 cubic inch, or $7.29 \mathrm{cc}$. The fuel occupies $6.79 \mathrm{cc}$ of this volume, leaving a void volume of $0.50 \mathrm{cc}$. This void volume, the mass of oxygen accumulated, and the temperature of the fuel capsule were used with the perfect gas law to calculate the internal pressure due to oxygen buildup as a function of time. This function is plotted in Fig. 5 as the calculated internal pressure in capsule.

The ultimate tensile stress and yield stress were determined as functions of time from the Haynes 25 data and the anticipated capsule temperature. From these values, the allowable capsule pressure was computed and plotted as a function of time in Fig. 5. The following relation was used:

$$
P=S \frac{R^{2}-r^{2}}{R^{2}+r^{2}}
$$

where

$$
\begin{aligned}
& \mathrm{P}=\text { allowable capsule pressure (psi) } \\
& \mathrm{S}=\text { ultimate tensile or yield stress of capsule material (psi) } \\
& \mathrm{R}=\text { minimum outside radius }(0.375 \mathrm{in} .) \\
& \mathrm{r}=\text { internal radius }(0.250 \mathrm{in} .)
\end{aligned}
$$

Maximum internal pressure after 360 days was computed to be 34,000 psi, a stress well below the ultimate allowable. That some yielding and consequent deformation of the capsule may take place after 200 days is evident from the plot, as the actual pressure exceeds the allowable yield after 200 days. However, internal pressure tests of a similar capsule indicated no deformation at 30,000 psi and $1100^{\circ} \mathrm{F}$ after 640 hours of aging (Ref.6). A pressure of 78,000 psi at room temperature was required to produce a measurable deformation, and 95,000 psi produced an increase in capsule diameter of only $0.7 \%$. Although the minimum wall thickness of the tested capsule was 0.193 inch 10.125 inch for the cerium capsule), test results indicate that either the formula used above or the allowable stresses for Haynes 25 are conservative. Sufficient deformation to affect generator performance during operational life will not take place. 


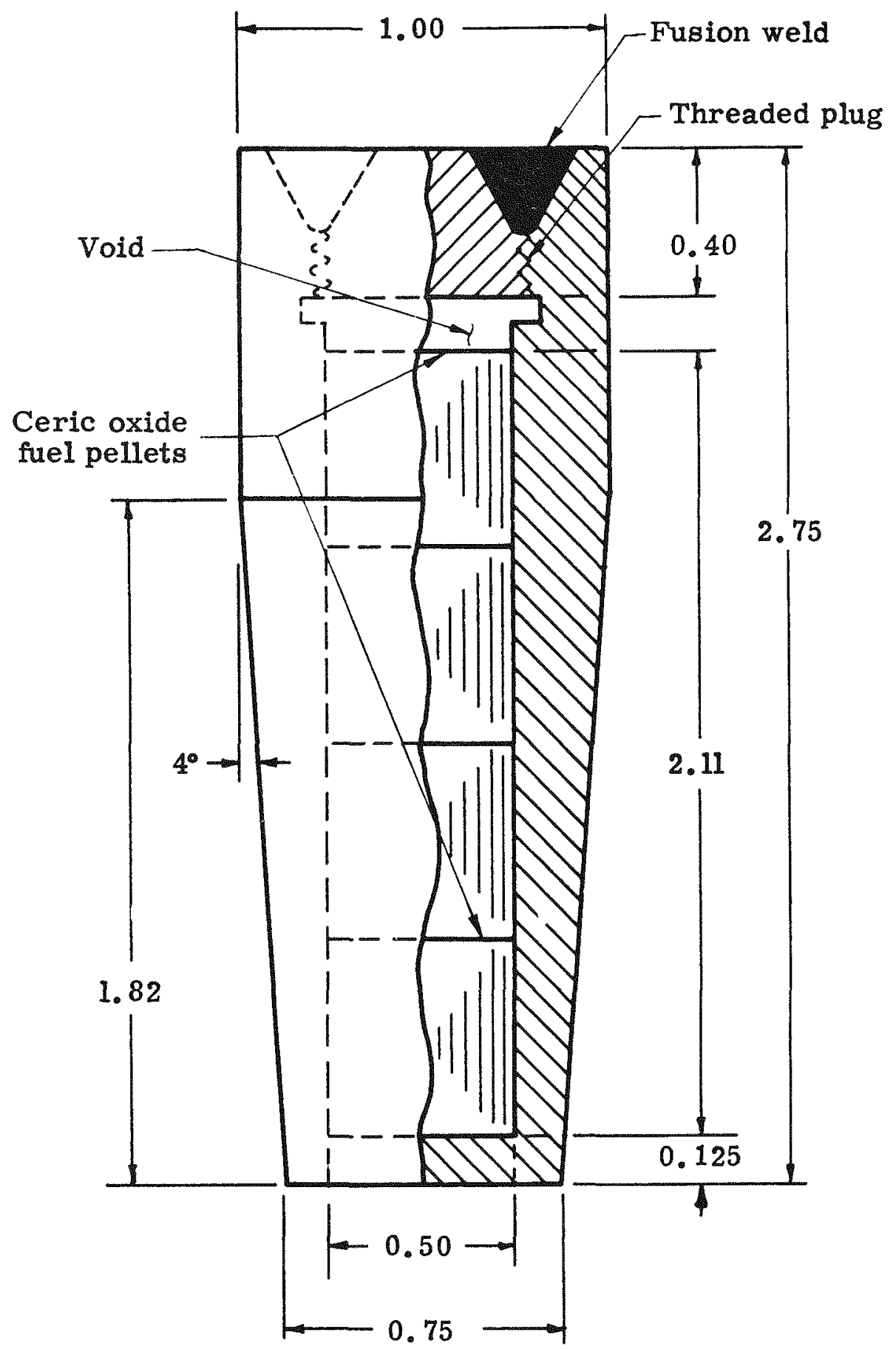

Fig. 4. Cerium Capale Configuration 


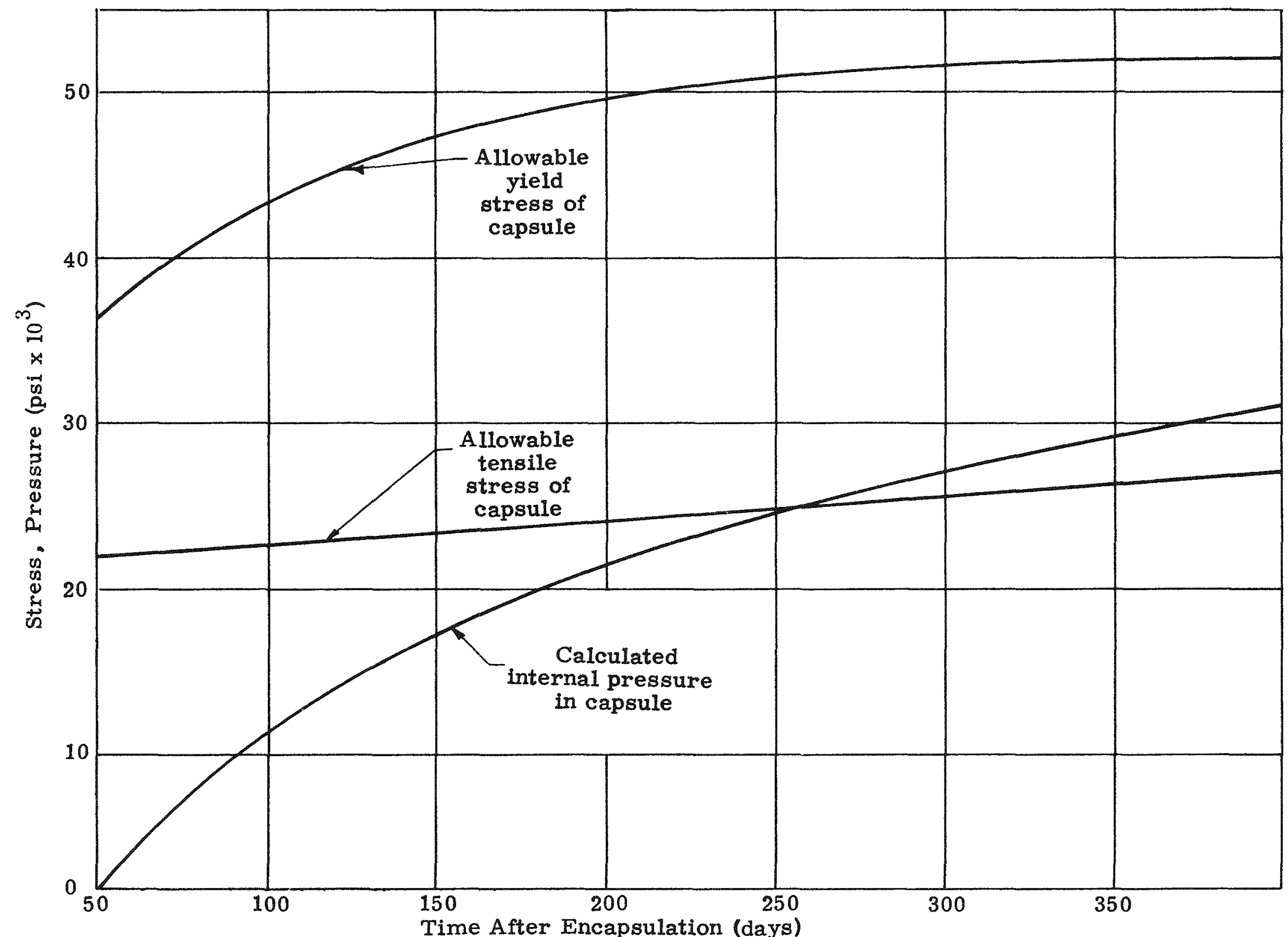

Fig. 5 Mechanical Integrity of Haynes 25 Capsule 


\section{THERMAL CONVERTER}

The thermal-to-electrical energy converter will remain identical to that originally used in the $3 \mathrm{M}-1 \mathrm{G}$ series. The lead telluride elements, approximately 1 inch long, have diameters of 0.210 inch for the $\mathrm{N}$-type and 0.225 inch for the P-type. These are paired to form 27 couples which are mounted in 6 vertical rows with a radial arrangement of 9 elements per row. Each element is loaded axially against a hot shoe by a 2-pound force provided by a spring and adjustment screw located in an aluminum cold junction ring. The hot shoe is iron which has been flame sprayed with aluminum oxide. The shoe makes the electrical connection between element pairs at the hot junction, while the oxide coat prevents current flow through the supporting hot junction cylinder. The couples are connected in series by copper wires at the cold junction and insulated electrically from the cold junction ring. Insulation is provided by an oxide coating (Martin Hard Coat) on the aluminum bearing caps located between the element end cap and the pressure spring. The hot junction cylinder supports the elements through the hot shoes and contains a tapered internal hole to receive the fuel capsule previously described. Mica sleeves are placed on the hot junctions of the elements to provide additional protection and insulation. This arrangement is illustrated in Fig. 6。

The remaining void inside the the generator shell is filled with JohnsManville Min-K 1301 insulation. This material is formed into solid pieces in the hemispherical ends and powdered in the thermoelctric area. A minor modification of one end-piece of insulation is required to allow the larger capsule to project beyond the hot junction cylinder. This projection, shown in Fig. 7, will increase the exposed capsule area by 0.5 square inch, allowing more heat to be lost to the outer shell. Should detailed heat transfer calculations show that this loss is sufficient to significantly affect overall generator efficiency, the height of the dome may be easily increased to provide compensating insulation thickness.

Copper, the original generator shell material, does not adequately resist corrossion when exposed to the shielding mercury. To take advantage of the information available from the mercury corrosion studies performed under Task 2 (SNAP IA program), a similar shell material, stainless steel, was selected for this application. The generator shell will radiate its heat to the shield container at a relatively low temperature; so a brief investigation of finishes or coatings with high emis sivity values was conducted. The recommended coating was a fused salt of sodium dichromate applied by the Armco Steel process. In this process the metal is immersed in molten sodium dichromate at a temperature of $740^{\circ} \mathrm{F}$. It produces an adherent, dull black oxide coating with heat immunity up to $800^{\circ} \mathrm{C}$ and resistance to mercury corrosion. 


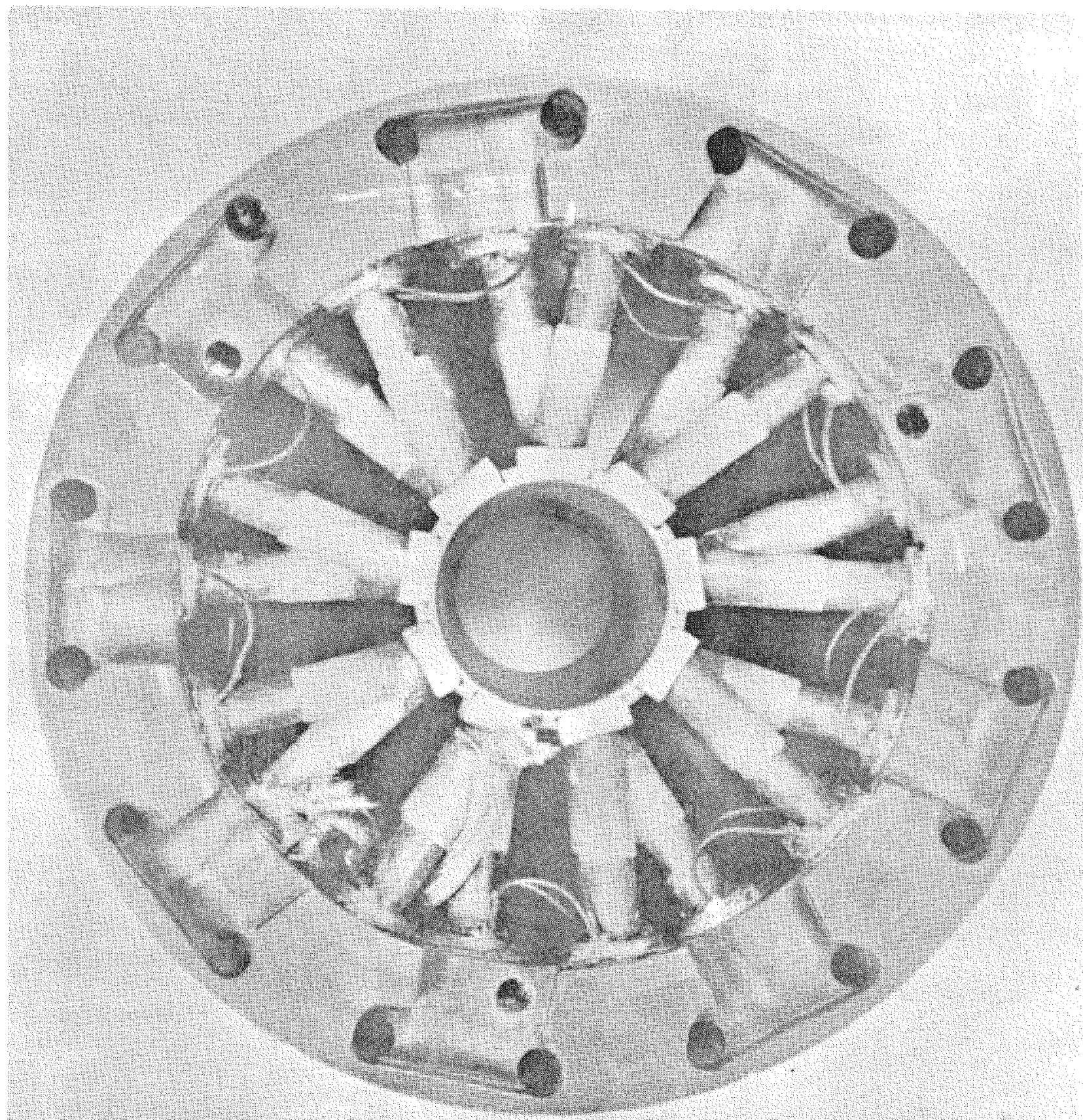

Fig. 6 Radial Element Arrangement 
Power output and thermocouple terminals

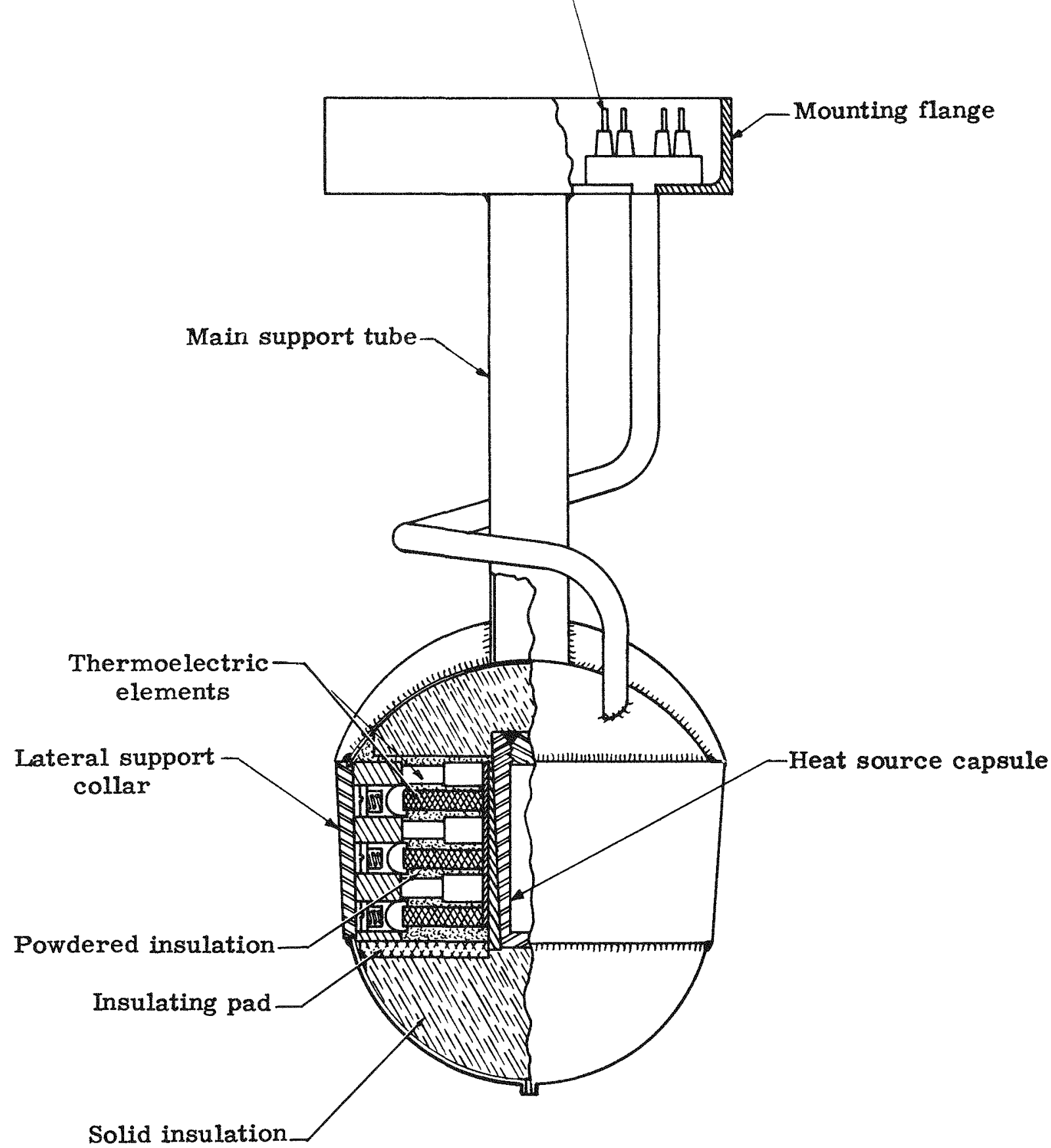


In addition to the material change, the shell was modified to provide supporting members connected to the shield container. In the modified design the primary support is a stainless steel tube welded to the upper end. Four reinforcing members, equally spaced around the tube, are attached to the tube and shell to distribute the load and prevent damage to the light-gauge hemispherical end during handling. Perforations in the tube allow mercury to enter and drain to provide shield material in this area. A second spiral tube protects the power and instrumentation leads. A tapered steel collar added around the cold junction engages a similar ring in the shield container to give lateral support.

\section{MERCURY SHIELD CONTAINER}

To utilize the procedures and equipment developed for the SNAP IA system, a similar mercury shield was designed for this unit. Radiation dose rates were calculated for a 9900-curie source of Cerium-144 with various mercury shield thicknesses. Dose rates 1 meter from the source were as follows.

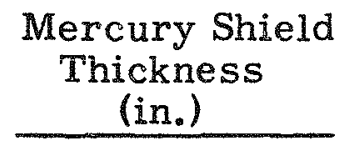

4

5

6
Dose Rate

$(\mathrm{mr} / \mathrm{hr})$

616

154

40

On the basis of these dose rates, 6 inches was selected as the minimum allowable shield thickness with reasonable maximum exposure times at the radiation level due to two sources.

With a 6-inch shield thickness and a 5.3-inch maximum external generator shell dimension (across the hemispherical ends), a shield container with an internal diameter of 17.3 inches is required. The container is designed to be fabricated from two identical hemispheres of stainless steel welded to a central ring. The lower hemisphere incorporates a mercury drain; and a mounting collar, large enough to allow inserting the generator in the sphere, is welded to the upper one. Open stainless steel members connect the inner and outer rings to provide lateral support for the generator. The shield container with the generator installed is shown in Fig. 8. 


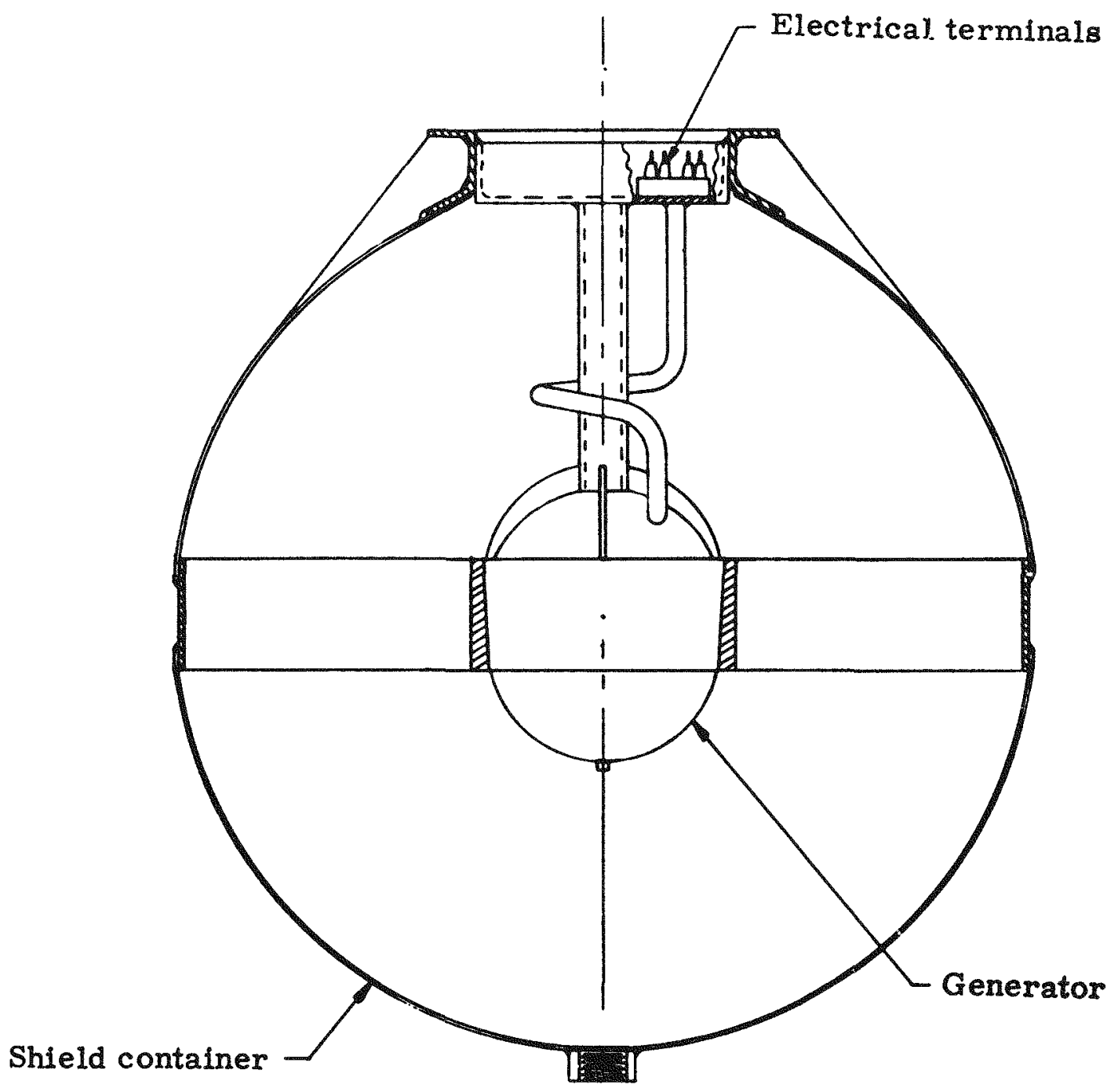

Fig. 8. Generator and Shield Container 


\section{E. LEAD SHIELD CONCEPT}

A second concept was investigated as a means of reducing the generator launch weight. In this concept, a lead cask provides the biological shield until the generator is installed in the missile by remote handling equipment. This eliminates the need for a shield container, with a consequent reduction in launch weight. Further, the generator requires fewer modifications since only mounting and handling provisions need be added to the basic configuration. A plug-in arrangement on one end of the generator permits structural mounting and electrical connections. A cone-shaped projection added to the other end allows the unit to be grasped by the remote handling equipment described later in this report. 
Blank 


\section{GENERATOR INSTALLATION}

One of the original objectives of this program was to use the design system as a prototype of the SNAP IA system. Therefore, a similar mounting location in the missile was selected. The missile system was assumed to consist of a booster stage and an orbit injection or second stage。 Both the mercury and lead cask shielding concepts were considered although primary emphasis was placed on the mercury system.

\section{A. MERCURY SHIELD CONCEPT}

Two units, each consisting of a generator assembled in its shield container, are used. The container mounting flange is attached to the secondstage missile structure adjacent to the engine. This arrangement is illustrated in Fig. 9. Two units are needed to satisfy the power requirements, and such an arrangement produces symmetrical loads on the missile structure. This is especially significant prior to launch, when an asymmetrical distribution of the weight of the mercury shield would produce significant moments in the booster structure. Upon separation of the second stage from the booster, both shield containers are exposed to allow radiation of unconverted heat directly to space.

The weight estimate for each unit is as follows:

$\underline{\text { Item }}$

Generator

Shield container

Generator supports

Mounting collar

Total per unit
Weight (lb) 5

12

5

$\underline{3}$

25

The total launch weight is approximately 50 pounds; mercury shield weight is 1250 pounds per unit. The booster structure is therefore required to support a total load of 2550 pounds prior to shield draining operations.

\section{B。 LEAD CASK SHIELD CONCEPT}

In this concept, a lead cask shields the generator unit until it is installed in the missile by remote handling equipment mounted on the gantry. Installation is the last operation prior to gantry removal. This concept eliminates the weight of the shield container and greatly reduces the 


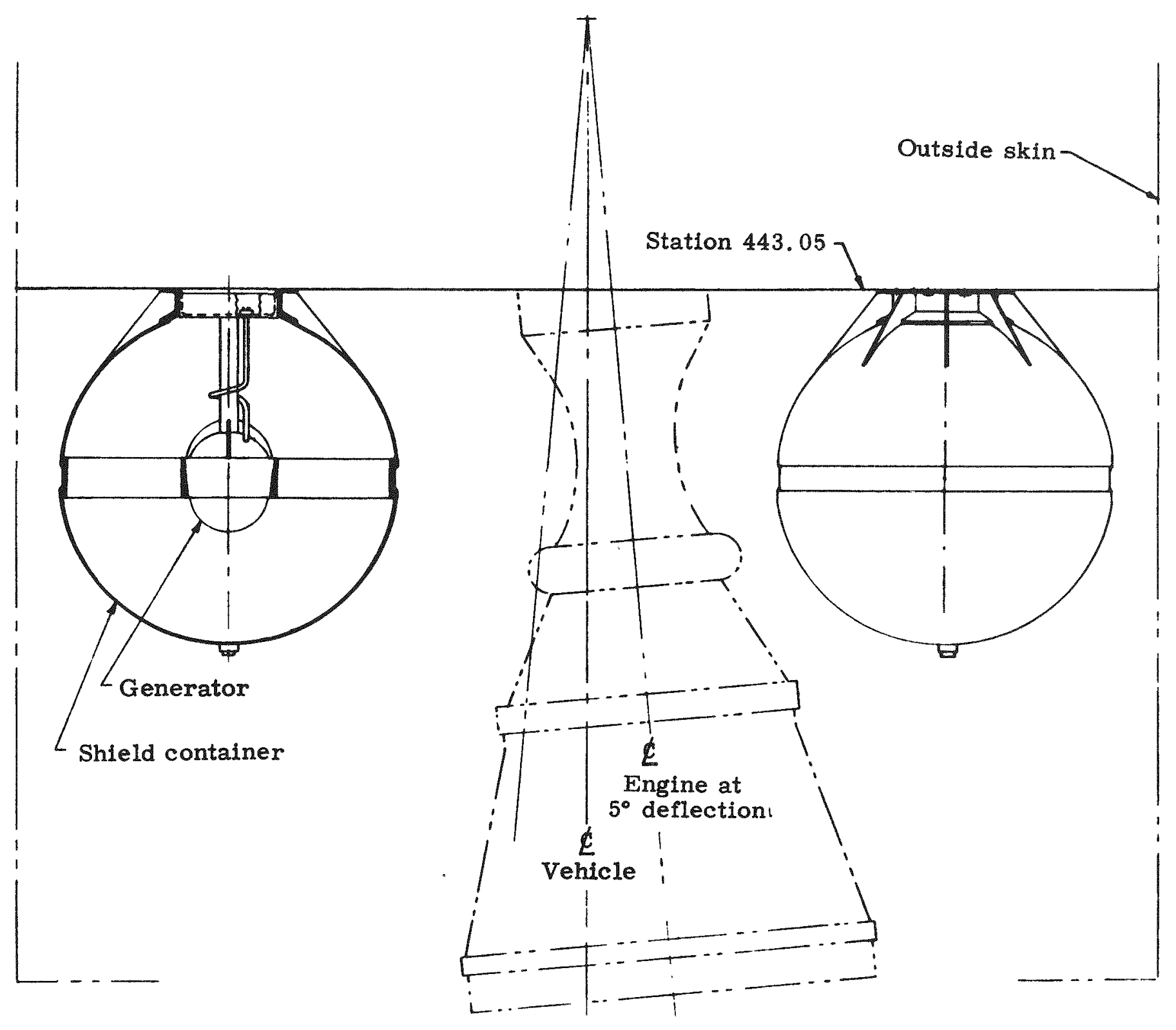

F1g. 9. Generator Installation 
strength required in the generator support hardware. The relation of the gantry, crane, vehicle and generator is shown in Fig. 10. The two casks containing the generators are hoisted to position by means of the gantry bridge crane. A cask shuttle dolly allows positioning of one cask on each side of the missile under the remote handling equipment. After positioning, the cask lid is removed by an actuator, exposing the generator and allowing the manipulator to grasp it. Figure 11 shows the manipulator arrangement. The manipulator, directed through a closed-circuit television system, inserts the generator in a receptacle in the missile. Plug-in provisions in the receptacle effect both the structural mounting and electrical connection simultaneously. The entry port in the vehicle skin is closed by the same manipulator. Although not evident in Fig. 11, manipulator mounting on the gantry is such that the complete assembly will move to the opposite side of the missile for installation of the second unit. The gantry then moves back in preparation for launch.

The weight estimate for each unit is as follows:

Item

Generator

Receptacle

Total per unit
Weight (lb)

\section{5}

3.0

7.5

Total launch weight will be approximately 15 pounds.

\section{DOSE RATES AND WORKING TIMES}

Dose rates prior to draining the mercury shield and prior to removal of the generator from the lead cask are similar. The radiation levels at various distances from two 9900-curie sources are listed in Table 3.

TABLE 3

Shielded Radiation Levels

Distance

(ft.)

2

3

4

5

10

20
Dose Rate

$(\mathrm{mr} / \mathrm{hr})$

206

90

52

34

8

2
Maximum Exposure Time (hr)

15

33

45

88

375

1500 


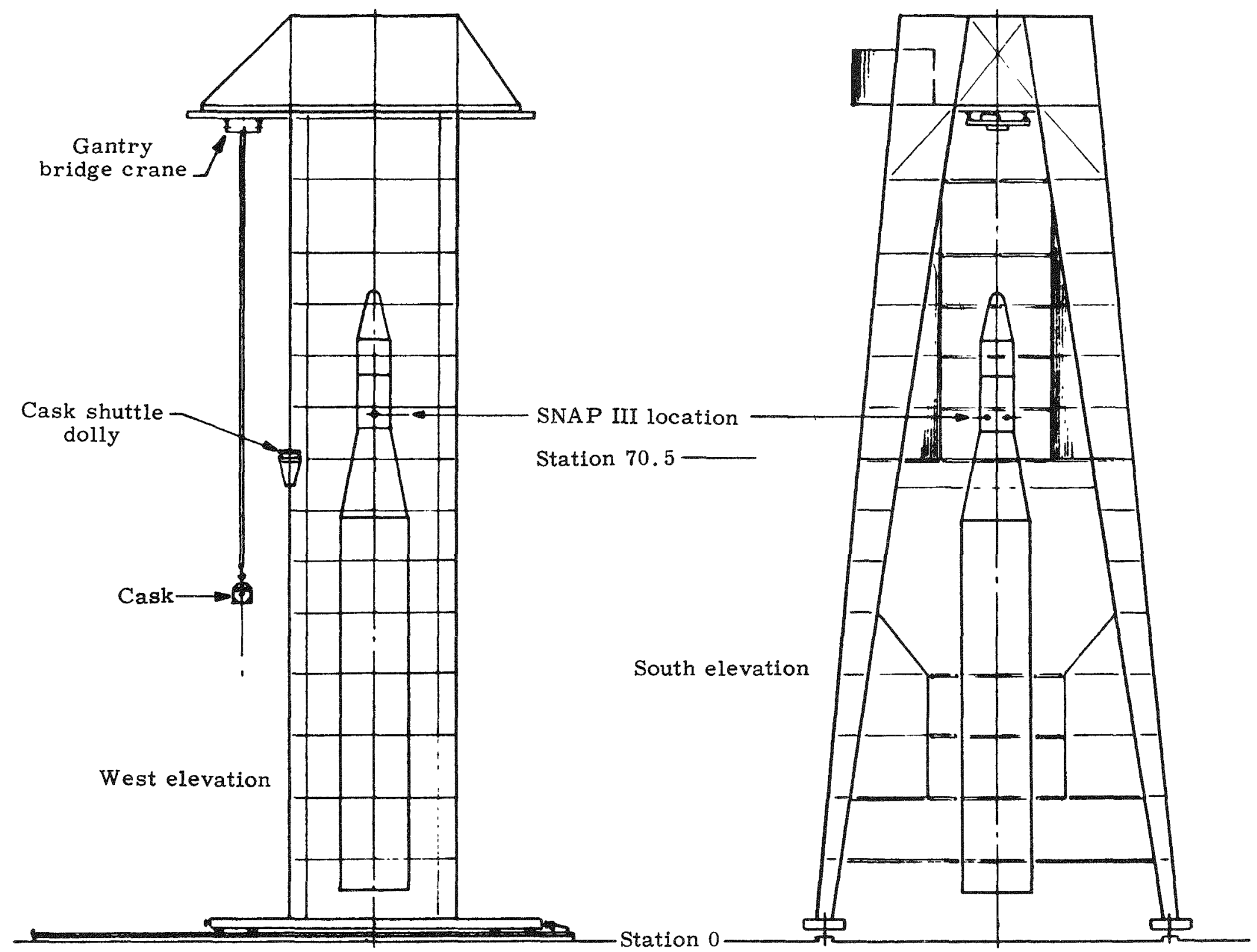




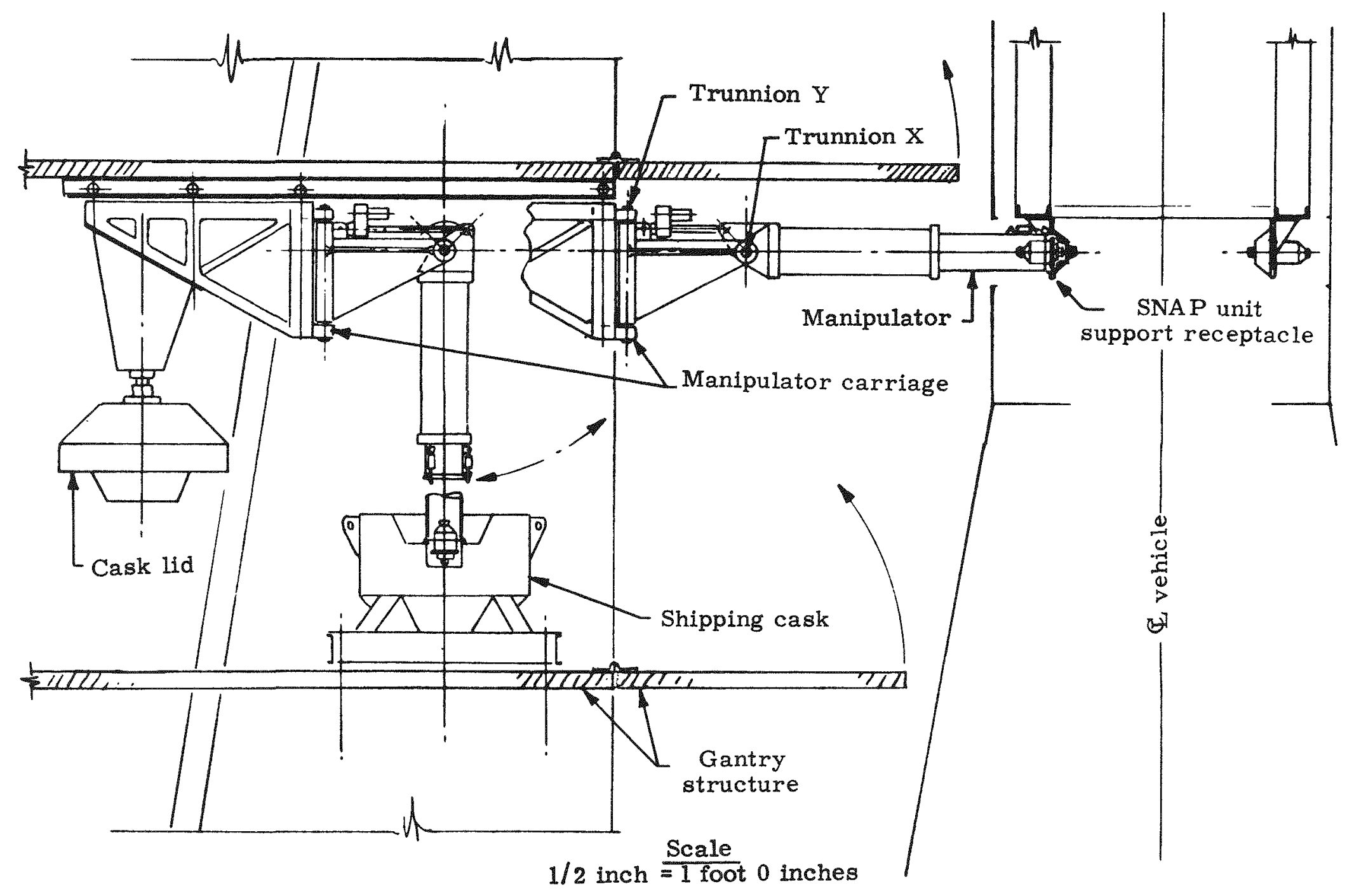

F1g. Il. Manfpulator Carriage Arrangement 
After the draining of the mercury shield or the removing of the generator from the cask, work may be performed on the pad in accordance with the distance and time limitations listed in Table 4. The generator is 10cated approximately 70 feet above the pad. If a countdown hold is imposed requiring workmen to remain at the distances listed for longer than the permissible times, the liquid shield must be returned to the shield container, or the units must be reinstalled in their casks.

Distance

(ft)

50

100
TABLE 4

Unshielded Radiation Levels

Dose Rate
(mr/hr)

5000

1240
Maximum Exposure Time (hr)

0.6

2.4 


\section{GENERATOR PERFORMANCE}

One design concept which uses cerium fuel requires that the generator be suspended within a spherical mercury container. After the mercury is drained, heat will be radiated from the generator shell to the surrounding sphere and from the surrounding sphere to space. The second concept dispenses with the shield container, allowing direct radiation from the generator surface to space. In the former process generator efficiency is slightly reduced because of increased hot junction temperatures. However, this concept is the one most likely to be adopted, and performance evaluations using this arrangement will be conservative. For these reasons the arrangement incorporating a surrounding sphere was the only one evaluated.

\section{A. SPHERE TEMPERATURE DETERMINATION}

The temperature of the shield container was determined by means of an equation developed by Goldman and Singer as follows (Ref. 8):

$$
\phi_{r}=\left[\frac{\left(1-\alpha_{V}\right)(1400)\left(\mu+\frac{\alpha_{E}}{\pi} \cos \rho\right)+\epsilon_{i r}(188.5)+x}{4{ }_{i r}^{\sigma}}\right]^{1 / 4}
$$

where

$$
\begin{aligned}
& \phi_{r}=\text { sphere temperature } \\
& x=\text { heat generation rate per unit area of cross-sectional area } \\
& \alpha_{\mathrm{V}}=\text { reflectivity } \\
& \mu \quad=\text { eclipse factor } \\
& \alpha_{E}=\text { earth's albedo } \\
& \rho \quad=\text { angle between orbit and sun } \\
& \epsilon_{i r}=\text { infrared emissivity } \\
& \sigma \quad=\text { Stefan-Boltzmann constant. }
\end{aligned}
$$


Biological shielding considerations, discussed in Section II-D of this report require that a minimum of 6 inches of mercury be provided. This requirement fixes the spherical container diameter at 17.3 inches. With this size and various assumed heat inputs from the radioisotope fuel, the heat generation rate per unit area of cross-section area $(x)$ was calculated. A polar and an equatorial orbit were assumed in the calculation of equilibrium temperatures since these provide the maximum and minimum heat inputs from the sun's radiation. The results of this evaluation are listed in Table 5. Although the orientation of the polar orbit continuously exposes the sphere to the sun's radiation, the temperature variation is negligible when compared to the equatorial orbit with a maximum eclipse factor.

\section{TABLE 5 \\ Equilibrium Temperatures}

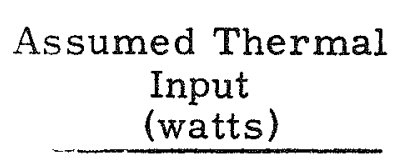

70

60

45

30
Sphere Surface Temperature $\left({ }^{\circ} \mathrm{F}\right)$

$\begin{array}{cc}\begin{array}{cc}\text { Equatorial } \\ \text { Orbit }\end{array} & \begin{array}{c}\text { Polar } \\ \text { Orbit }\end{array} \\ -24 & -17 \\ -33 & -25 \\ -49 & -42 \\ -60 & -58\end{array}$

\section{B. GENERATOR OUTPUT}

Temperatures at the generator shell may be calculated for various thermal inputs and sphere temperatures. Generator performance, however, is not a linear function of these temperatures since thermoelectric characteristics are also temperature-dependent.

A SNAP III generator suspended in an evacuated sphere gave the required accurate performance data. A stainless steel sphere 24 inches in diameter was used in the tests. After evacuation, the sphere and generator assembly was placed in a cold chamber for regulation and selection of sphere temperatures. A summary of test results is given in Appendix A. The measured power input was corrected for heater power factor and heat losses through heater and instrumentation leads; the corrected values are listed in the last column in Appendix A. 
Since the test sphere was larger than the 17-inch diameter shield container, the test data must be correlated before direct application. To relate the shell diameters and temperatures, the following general equation for radiative heat transfer can be used:

$$
\mathrm{q}=\mathrm{FA} A_{1} \sigma\left(\mathrm{T}_{1}^{4}-\mathrm{T}_{2}^{4}\right)
$$

where

$$
\begin{aligned}
& q_{1}=\text { heat flow } \\
& A_{1}=\text { surface area of the heat source (generator shell) } \\
& \sigma=\text { Stefan-Boltz mann constant } \\
& T_{1}=\text { heat source temperature (generator shell) } \\
& T_{2}=\text { heat sink temperature (test sphere or shield sphere) } \\
& F=\text { view factor between heat source and sink. }
\end{aligned}
$$

The view factor for two concentric spherical surfaces is given by the following equation:

$$
F=\frac{1}{\frac{1}{\epsilon_{1}}+\frac{A_{1}}{A_{2}}\left(\frac{1}{\epsilon_{2}}-1\right)}
$$

where

$$
\begin{aligned}
& \epsilon_{1}=\text { emissivity of the heat source (generator shell) } \\
& \epsilon_{2}=\text { emissivity of the heat } \text { sink } \\
& A_{2}=\text { surface area of the heat sink }
\end{aligned}
$$

From Eqs (1) and (2), separate equations for the test and actual cases may be established and solved simultaneously to obtain the following:

$$
T_{t}^{4}=T_{S}^{4}+\frac{q}{A_{1} \sigma}\left[\frac{1}{\epsilon_{1}}+\frac{A_{1}}{A_{S}}\left(\frac{1}{\epsilon}-1\right)-\frac{1}{\epsilon_{1}}-\frac{A_{1}}{A_{t}}\left(\frac{1}{\epsilon_{t}}-1\right)\right]
$$


where

$$
\begin{aligned}
& T_{t}=\text { temperature of test sphere } \\
& T_{S}=\text { temperature of shield container } \\
& A_{S}=\text { area of shield container } \\
& A_{t}=\text { area of test sphere } \\
& \epsilon_{s}=\text { emissivity of shield container } \\
& \epsilon_{t}=\text { emissivity of test sphere. }
\end{aligned}
$$

Since the test sphere and shield container materials are identical, their emissivities may be assumed to be approximately equal as follows:

$$
\epsilon_{S} \approx \epsilon_{t}=\epsilon
$$

Substitution according to Eq (4) simplifies Eq (3) as follows:

$$
T_{t}^{4}=T_{s}^{4}+\frac{q}{\sigma}\left(\frac{1}{\epsilon}-1\right)\left(\frac{1}{A_{s}}-\frac{1}{A_{t}}\right)
$$

Inspection of Eq (5) shows that the second term is very small in comparison to the fourth power of the temperature in view of the spherical areas in question. Therefore, the temperature of the test and shield containment spheres will be approximately equal for any given heat flux. It is also apparent from the test data given in Appendix A that the generator is relatively insensitive to minor temperature variations of the surrounding sphere。

As a result of the conclusions developed in the foregoing analysis, the test data were used directly to determine generator performance characteristics. Through a process of interpolation and cross plotting, generator outputs and temperatures were determined for the power inputs and sphere temperatures listed in Table 5. Outputs and temperatures as functions of power input are plotted in Fig. 12 。

The hot junction temperature should be limited to $1100^{\circ} \mathrm{F}$ to avoid damaging the thermoelectric elements. The maximum power input, according to Fig. 12, should be 67 watts, and the corresponding power output, 3.85 watts. The temperature limit applies, however, only when the generator is in a vacuum and only radiative heat transfer takes place. Convective air currents tend to lower surface temperatures while 


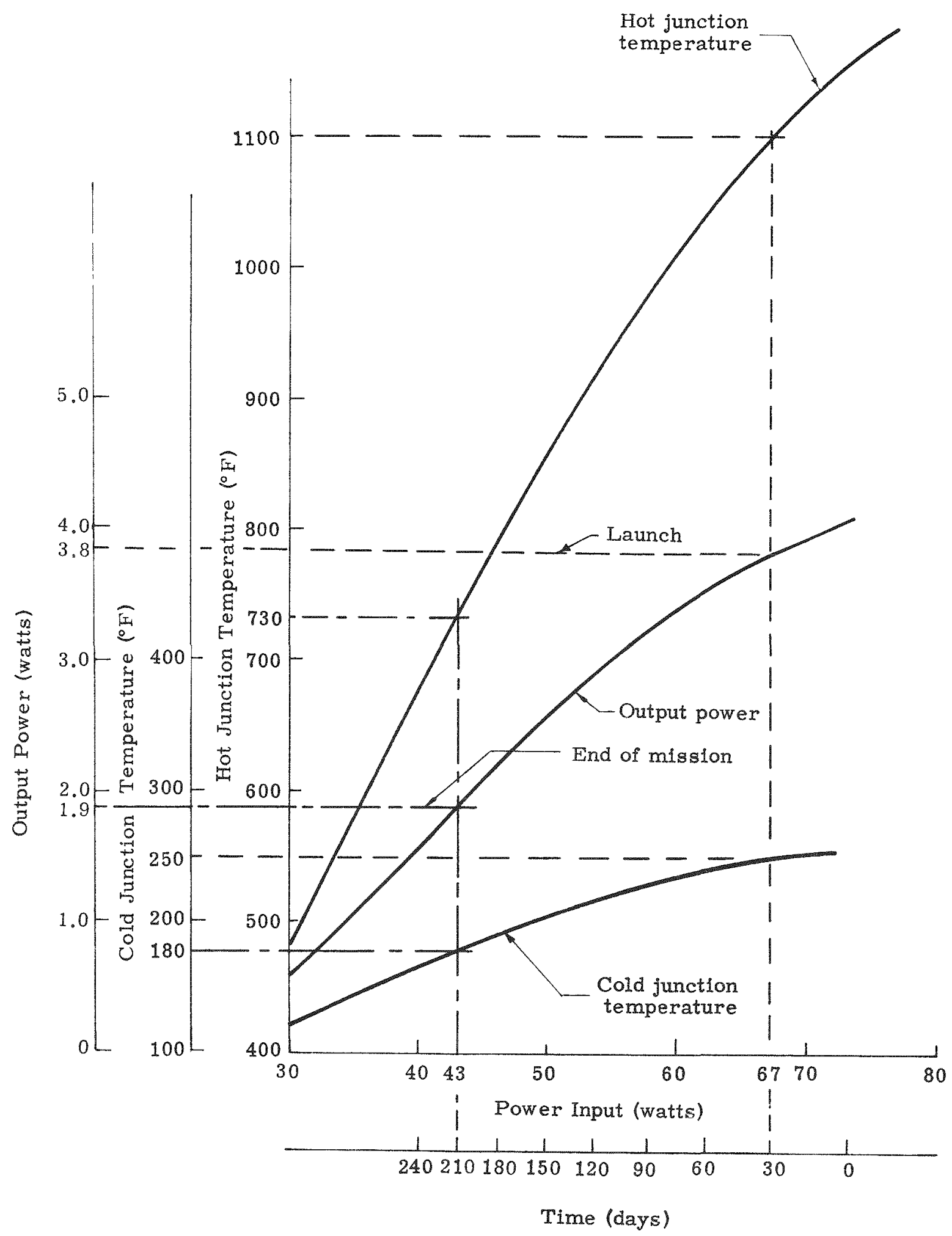

FIg 12. Generator Periornance 
the generator is in the atmosphere. Short circuiting the unit prior to launch also lowers the hot junction temperature. The 67-watt input is a limit only at the time of launch. A 30-day period is assumed to elapse between generator loading and launch. The initial quantity of isotope to be encapsulated may be determined from the following relationship:

$$
P=P_{0}-\lambda t
$$

where

$$
\begin{aligned}
& \mathrm{P}=\text { isotope thermal energy at any time } t \\
& \mathrm{P}_{0}=\text { isotope thermal energy at } \mathrm{t}=0 \\
& \lambda=\text { decay constant. }
\end{aligned}
$$

Initial thermal energy at the time of capsule loading was computed from $\mathrm{Eq}(6)$ to be 72 watts. This value was used to determine the curie load and capsule dimensions developed in Chapter II of this report. Equation (6) was also used to calculate a time scale equivalent to the thermal input plotted as the abscissa of Fig. 12. For a 6-month mission (180 days), the power input would be 43 watts with an output of 1.90 watts per generator. 


\section{GROUND HANDLING PROCEDURES}

Handling procedures for this system may be logically divided into three phases according to the areas of operation. The equipment and procedures discussed here apply primarily to the mercury shield concept but, with modifications, may also be utilized for the lead cask concept. Major differences exist only at the launch pad, and, since these procedures and equipment are presented in Chapter III of this report, no further discussion of the lead cask concept will be included here. In sequence, the unit will be loaded at the fuel processing facility, tested at the Martin Nuclear Facility and installed in the missile at the launch pad.

\section{A。 FUEL PROCESSING FACILITY}

All operations involved in loading the generator must be accomplished by remote manipulation in a hot cell until the generator is loaded in its shipping cask. After the cerium compound is prepared and pressed into pellets, they are inserted into the capsule, which is closed by a screw plug。 The capsule is sealed by welding the plug in place in a fixture. Smear and radiation tests determine whether the external capsule surface is contaminated. A calorimeter check is required to define the exact thermal output of the isotope load. If all checks are satisfactory, the capsule is inserted, the insulation replaced and the generator sealed with a solder joint. Seal integrity is checked and the unit is prepared for operation. After successive evacuation and back filling operations using an argon and hydrogen gas mixture, the tube is pinched off and sealed. Unit configuration is as illustrated in Fig. 7. This assembly is then inserted in the shield container and secured by a weld around the mounting flange as shown in Fig. 8. Since the shield container will limit free passage of cooling air over the generator surface, water is added as a heat transfer medium to prevent overheating of the thermoelectric elements. The complete assembly is then inserted and secured in the shipping cask. This procedure is diagrammed in step fashion in Fig. 13.

Preparation of the cask and method of shipment will be similar to the procedures developed for the SNAP IA unit (Ref。9). The major difference is that the completely assembled unit, rather than only the fuel core, is shipped in this case. This arrangement increases the weight of the cask but obviates the necessity for special assembly equipment at the launch site. Provisions are incorporated in the cask to allow filling or draining of the mercury shield prior to removal of the generator from the cask. Cask volume and weight can be considerably reduced if the mercury shield remains in the cavity surrounding the generator during shipment。 Using mercury as a shield material raises the possibility that a shipping accident may cause leakage with a consequent reduction in 


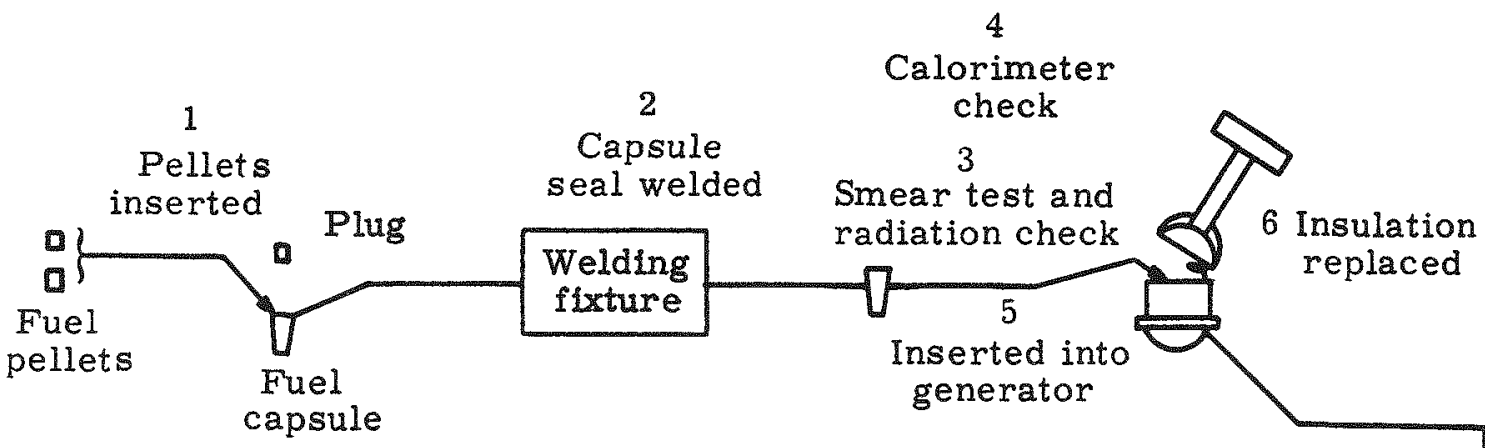

11

12 Water added Generator installed and

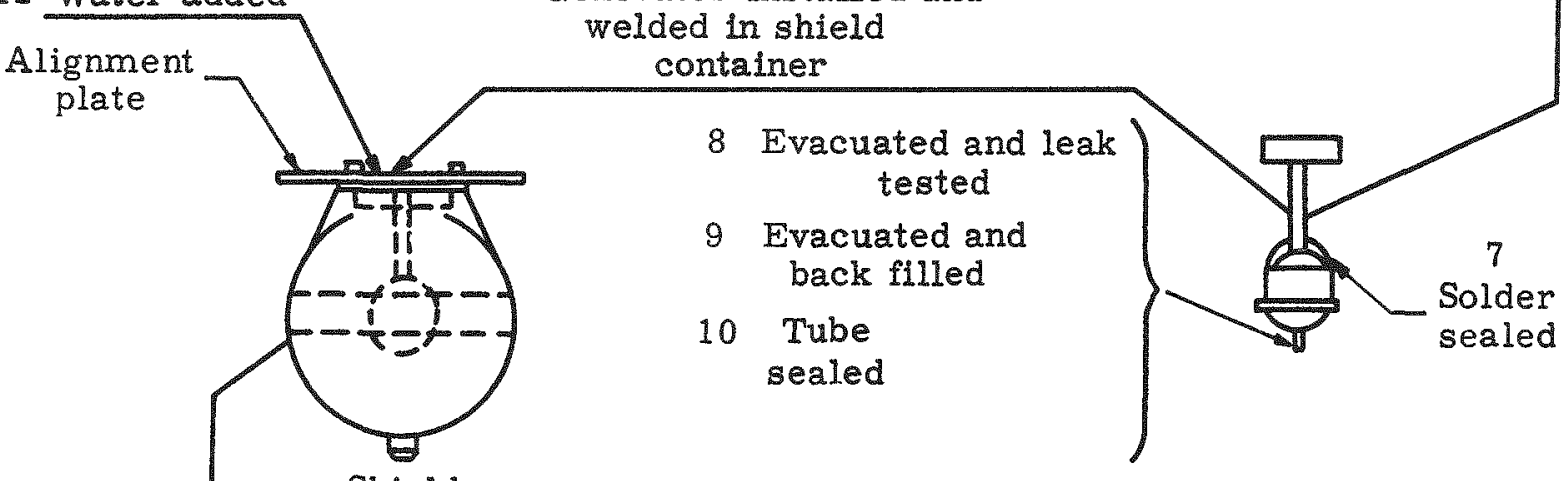

Shield

container

Shield container inserted

into shipping cask and cask secured

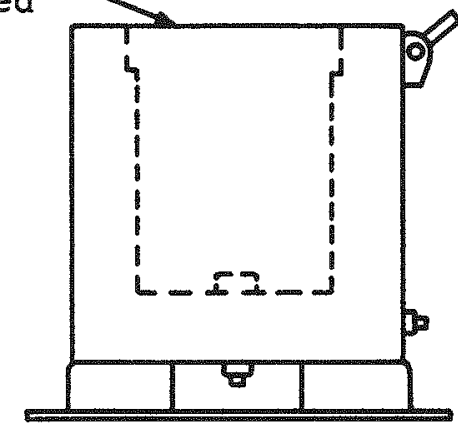

14 Radiation monitored

15 Shipment

F1g. 13. Ground Handing Flow Dlagram--Fuel Process Facility 
or complete loss of shielding. In the interests of safety, the increased weight is accepted as essential to maintain shield integrity. The water included as a heat transfer medium may be lost in a similar incident; however, capsule integrity would not be affected although the thermoelectric materials may be damaged by the resulting temperature rise. Cask configuration is shown in Fig.14。 The weight of the cask is approximately 9100 pounds. Details of the arrangement that allows operation of the drain plug are given in Fig. 15. The mercury and water handling equipment developed for the SNAP IA system can be used (Ref.9)。 The unit will be shipped to the Martin Nuclear Facility for performance testing.

\section{B. MARTIN NUCLEAR FACILITY}

Upon receipt of the shipping cask at the Martin Nuclear Facility, mercury will be introduced to replace the water in the shield container before the generator assembly is removed from the cask. A simple handling dolly is used to facilitate movement of the unit after removal from the cask.

Testing of the unit depends on the time available prior to delivery to the launch site and the facilities available. A minimum program requiring no additional facilities consists of a simple performance check. Hot and cold junction temperatures and generator output for various load resistances can be determined with the shield container at ambient temperature. Cold junction temperature can be varied somewhat by circulating and cooling the mercury shield material. A complete performance check requires a hot cell with mercury handling and temperature control equipment installed. Draining the shield, evacuating the shield container and controlling its temperature create operating conditions simulating those in space. After satisfactory tests have been completed, the unit is returned to the cask. Shipping preparations for transfer to the launch pad are identical to those previously described. Figure 16 is a flow diagram of this phase of operation.

\section{C。 LAUNCH SITE}

At the launch site, mercury is again added to replace the water in the shield container. After removal from the cask, the generator units are positioned and installed in the vehicle by a ground handling dolly. This procedure is diagrammed in Fig. 17. The ground handling dolly can be a double unit as designed for the SNAP IA; however, a single dolly, as illustrated in Fig。18, will provide maximum flexibility for minimum cost. Figure 19 shows the SNAP IA arrangement for vehicle installation. 


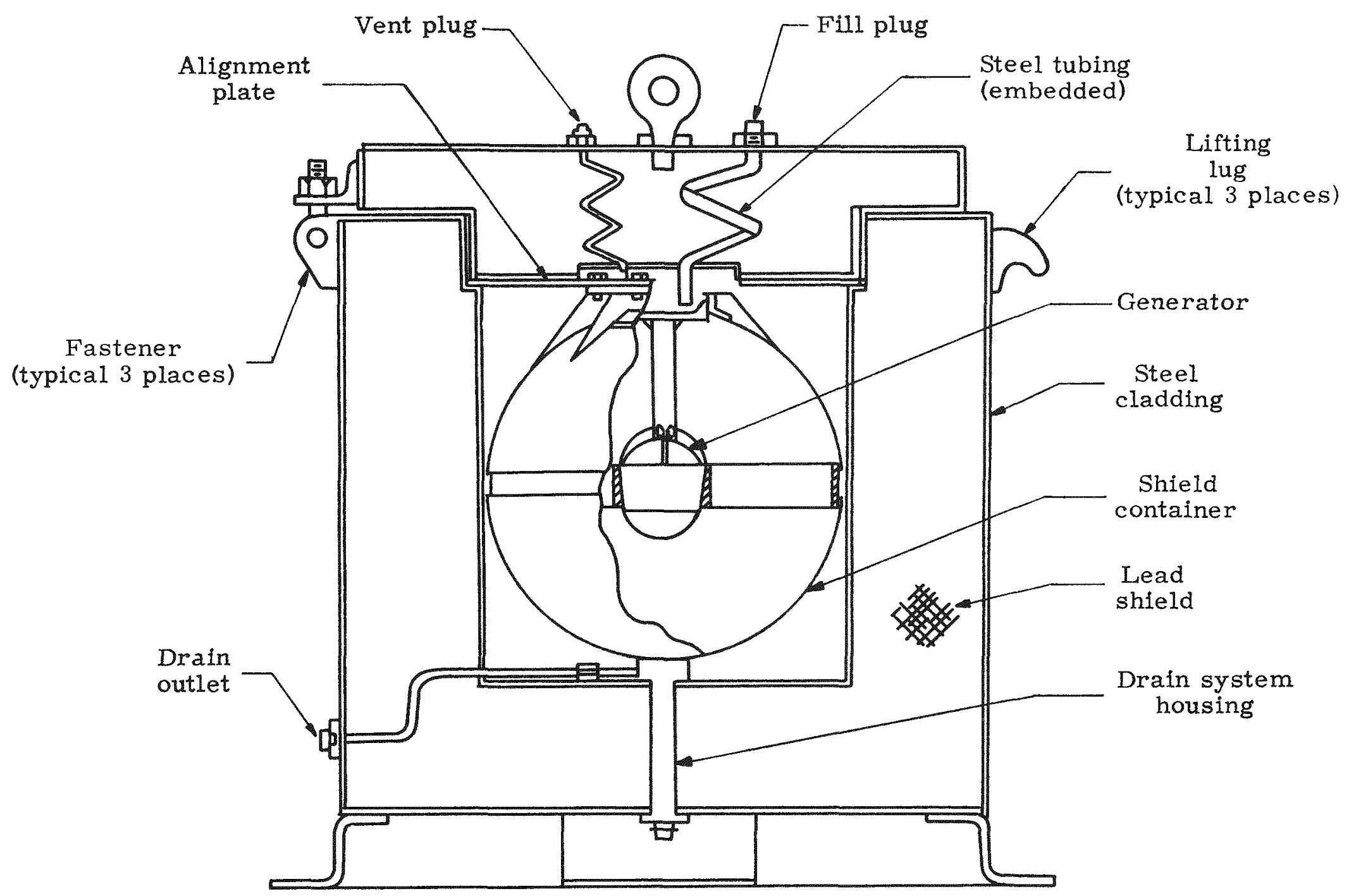

Fig. 14. Shipping Cask for Cerium Fueled System 


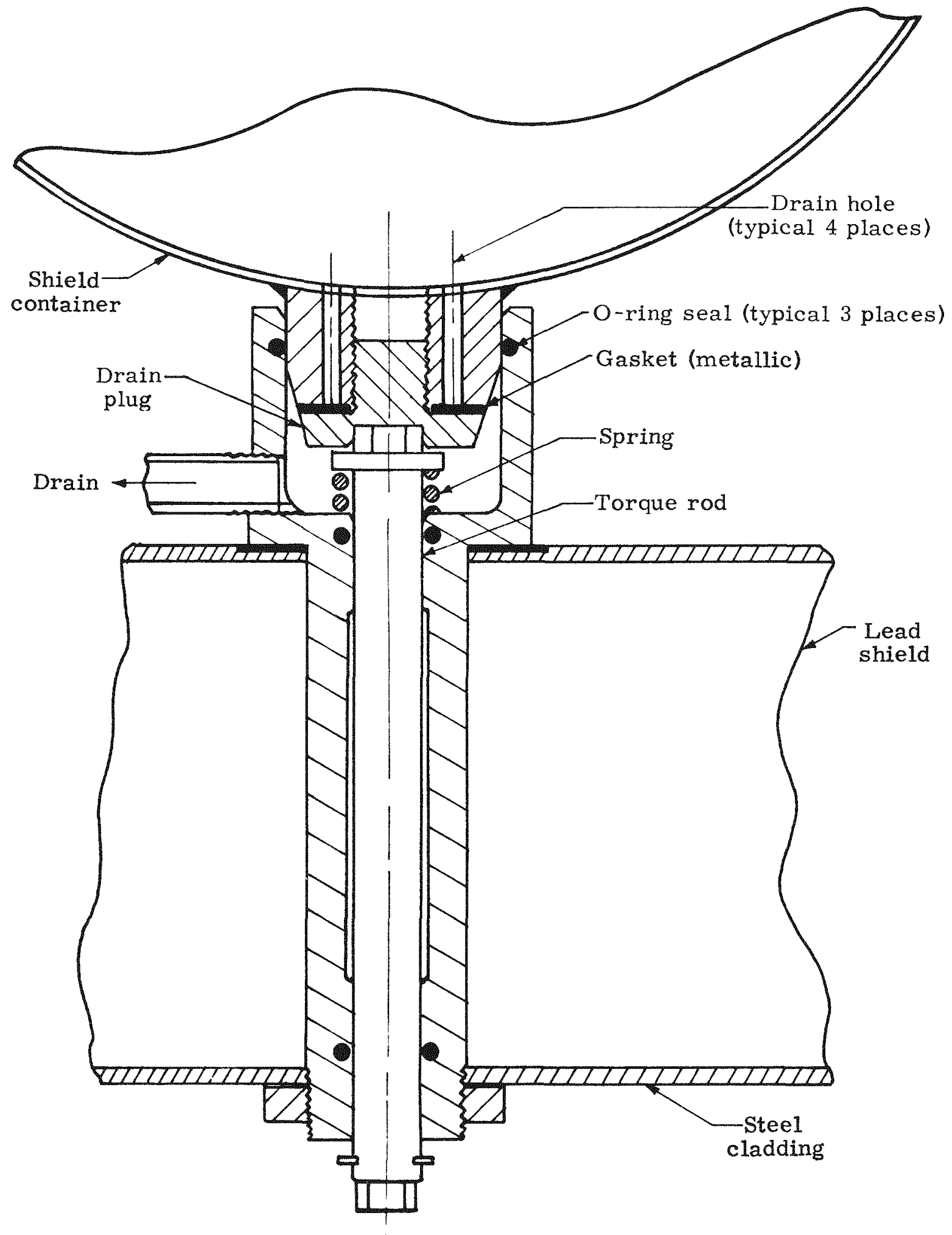

Fig. 15. Detall of Drain System 
16

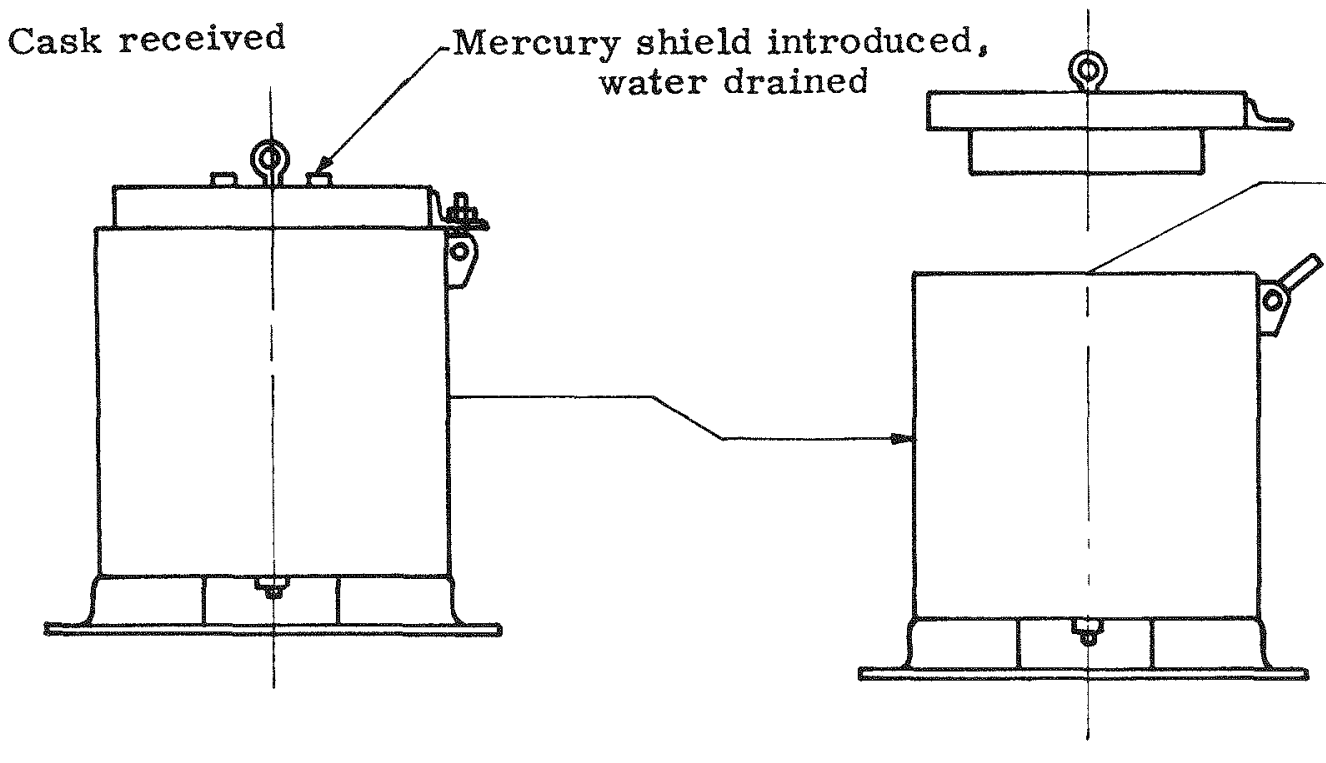

17

Shield container removed to dolly

19

Final generator test

20

Generator returned to cask

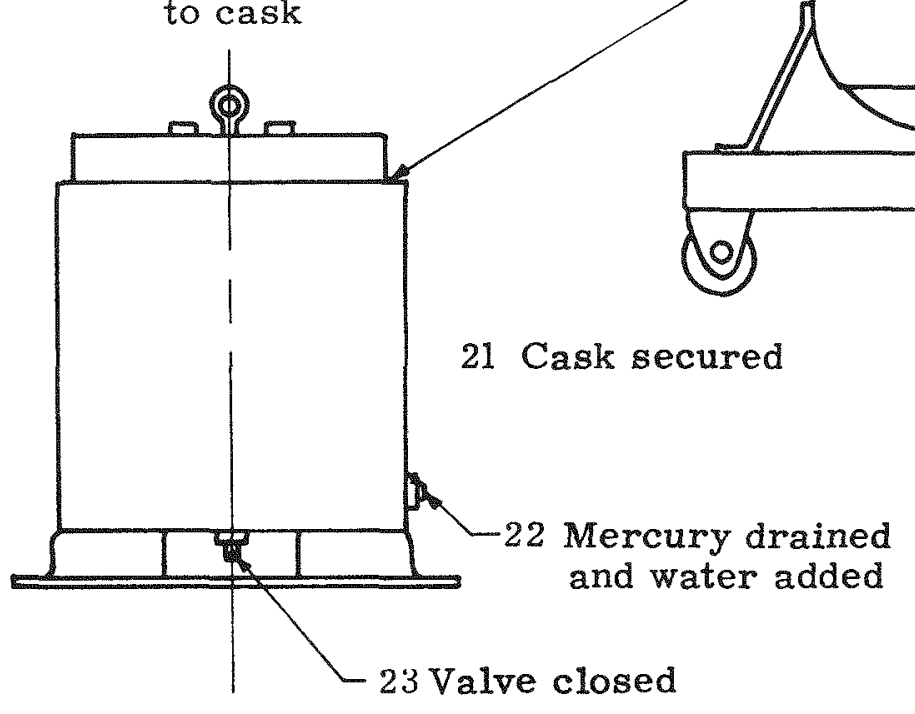

F1g. 16. Ground Handling Flow Diagram--Martin Nuclear Facility 


\section{Launch Site}

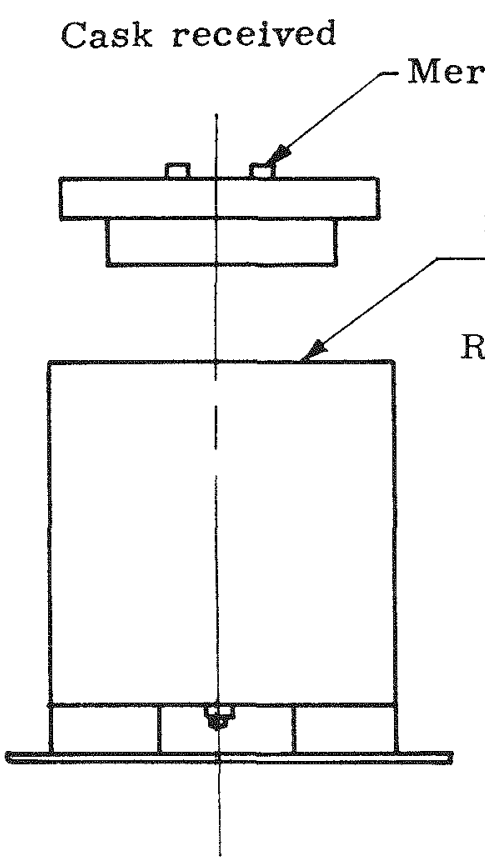

24

Mercury introduced and water drained

25

Shield container

removed to dolly

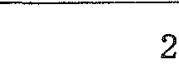

Radiation monitored
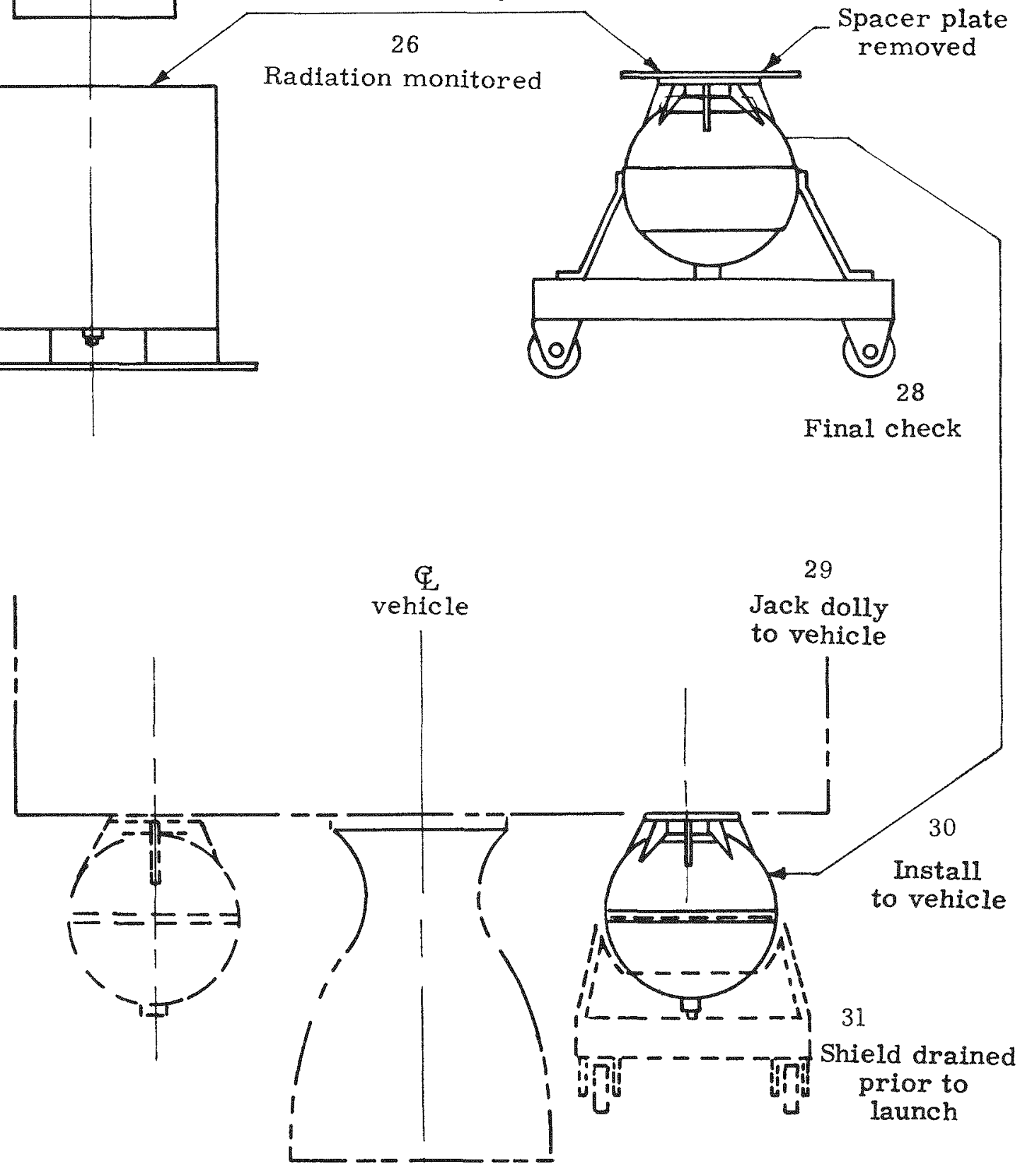

F1g. 17. Ground Handling Flow Diagram--Launch Site 


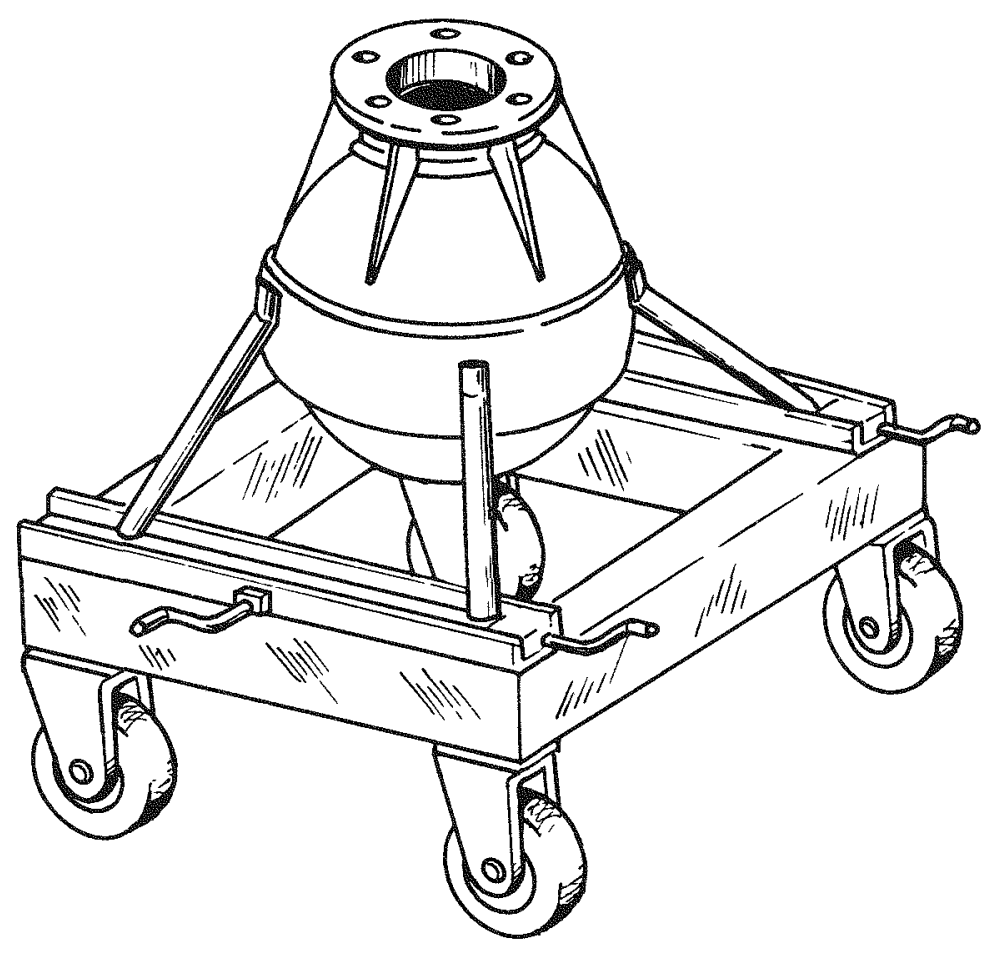

F1g. 18. Ground Handling Dolly for Cerium Fueled System

After installation, the final stage missile is hoisted to its position on the booster stage. Mercury handling systems and procedures developed for the SNAP IA can be used for the conceptual generator (Ref. 10). 


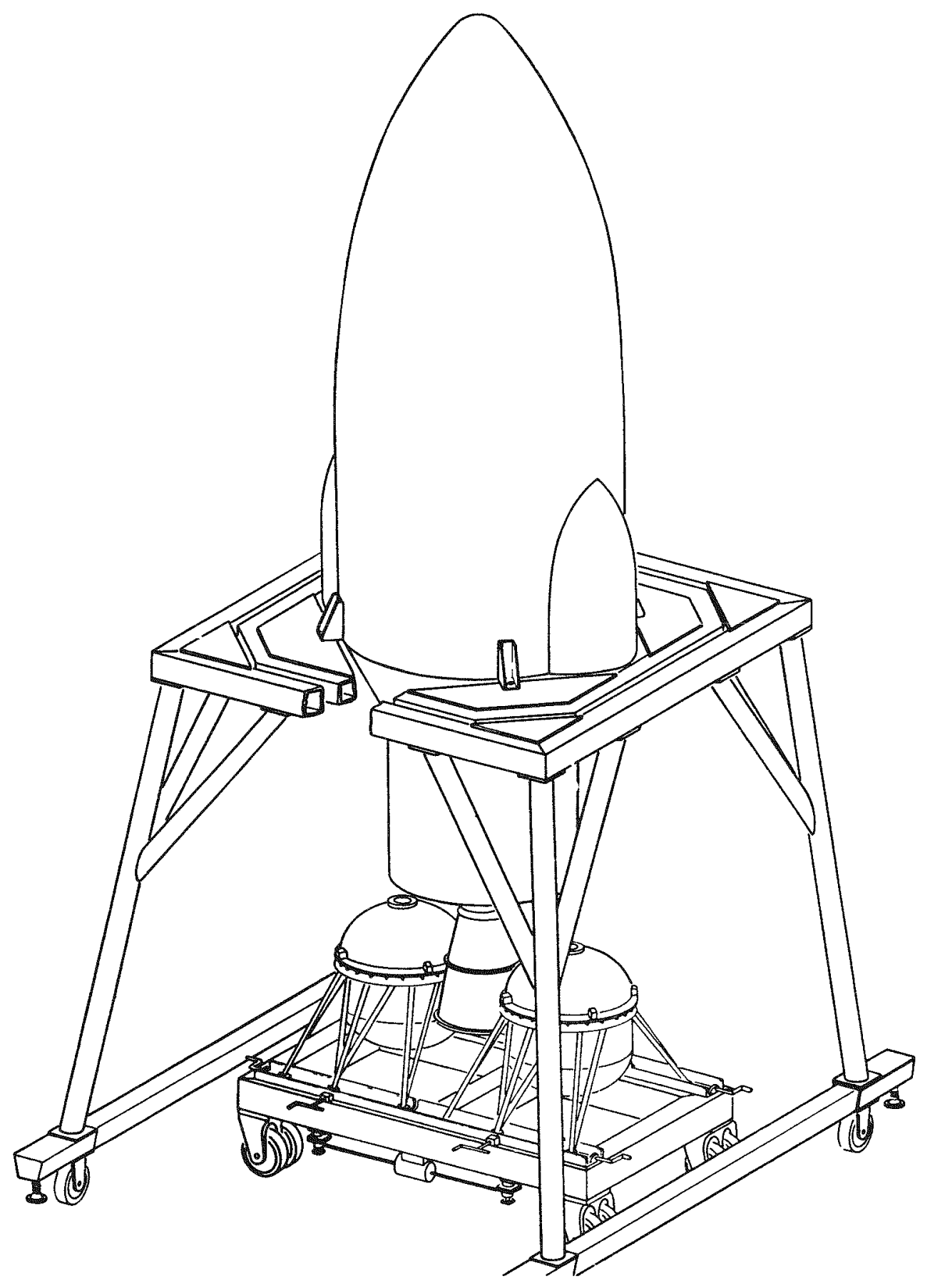

F1g. 19. SNAP IA Vehicle InstaIlation Arrangement 
Blank 


\section{CONCLUSIONS}

This system will provide a low power electrical source utilizing a thoroughly tested and proven thermoelectric generator. Although some modification of the generator is required, a short lead time would be possible provided the SNAP IA handling equipment is available for use.

A major conclusion derived from the study of a cerium fueled system is that its specific power is not competitive with other systems in its power range when a mercury shield is used. This results from the relation between source strength and shield thickness. The SNAP IA, in which a source of 880,000 curies requires a shield of 10 inches, has a much greater specific power than this conceptual generator in which a 9900-curie source requires a 6-inch shield thickness. Specific power in the lead cask concept is increased only at the expense of more complicated installation equipment and restrictive launch procedures.

A logical application for this system would be its use as a prototype for the SNAP IA. It would allow an operational checkout of mercury handling equipment and countdown procedures at the launch pad with a much lower source strength than SNAP IA while providing power for a useful purpose. Fuel preparation procedures, characteristics and specific power could also be prototyped at a much lower level of activity. 
Blank 


\section{VII。 REFERENCES}

1. Wilson, $R$ 。 J. Program Plan, Task 5, Subtask 5.5, "Thermoelectric 2- to 5-Watt Operational Generator for Space Use, "The Martin Company, MND-P-2175, Revisions 1 and 2。

2. Millette $\mathbf{J}_{\circ 2}$ Statement of Work, Task 5, Subtask 5.5, Advanced Technology Program, The Martin Company, MND-P-2199.

3. Dix, $G_{\circ}$ and Hagis, $W_{\circ}$ " Final Safety Analysis Report, Task 2 Radioisotope Powered Thermoelectric Generator," The Martin Company, MND-P-2352。

4. Nuclear Safety Analysis Unit, "Preliminary Safety Analysis--Low Power Cerium-144 Generator," The Martin Company, MND-P-2363.

5. Dick, P.J., "SNAP IA Fuel Core Material Development Summary," The Martin Company, MND-P-2349.

6. Wilson, $\mathrm{R}_{\mathrm{c}} \mathrm{J}_{\circ}$ "Operational Testing of SNAP III, The Martin Company, MND-P-2368。

7. Haynes Stellite Company, "Haynes Alloy No. 25," March 1959.

8. Goldman, D. F , and Singer, $S_{\circ} F_{\circ}$ Studies of a Minimum Orbital Unmanned Satellite of the Earth, Part III, "Radiation Equilibrium and Temperatures."

9. Reilly, M. J., "Preliminary Technical Manual Loading, Shipping and Testing Procedures for Task 2 Isotopic Powered Thermoelectric Generator," The Martin Company, MND-P-2316.

10. Klein, L. T. "Interim Report on Safety Procedures for the Task 2 Thermoelectric Generator, "The Martin Company, MND-P-2335. 
APPENDIX A (Ref. 6)

SUMMARY OF GENERATOR PERFORMANCE TEST RESULTS

\begin{tabular}{|c|c|c|c|c|c|c|c|c|}
\hline $\begin{array}{c}\text { Test Shell } \\
\text { Temperature } \\
\left({ }^{\circ} \mathrm{F}\right)\end{array}$ & $\begin{array}{l}\text { Measured } \\
\text { Power } \\
\text { Input } \\
\text { (watts) }\end{array}$ & $\begin{array}{l}\text { Output } \\
\text { Voltage } \\
\text { at Maximum } \\
\text { Power } \\
\text { (volts) }\end{array}$ & $\begin{array}{l}\text { Maximum } \\
\text { Output } \\
\text { Power } \\
\text { (watts) }\end{array}$ & $\begin{array}{c}\text { Chamber } \\
\text { Pressure } \\
\text { (microns of } \mathrm{Hg} \text { ) }\end{array}$ & $\begin{array}{l}\text { Source } \\
\text { Temperature } \\
\left({ }^{\circ} \mathrm{F}\right)\end{array}$ & $\begin{array}{l}\text { Hot Junction } \\
\text { Temperature } \\
\left({ }^{\circ} \mathrm{F}\right) \\
\end{array}$ & $\begin{array}{c}\text { Cold Junction } \\
\text { Temperature } \\
\left({ }^{\circ} \mathrm{F}\right)\end{array}$ & $\begin{array}{c}\text { Corrected } \\
\text { Power Input } \\
\text { (watts) }\end{array}$ \\
\hline-100 & 15 & 0.25 & 0.081 & 670 & 141 & 137 & 5 & 14.06 \\
\hline-100 & 30 & 0.85 & 0.540 & 645 & 402 & 394 & 78 & 27.51 \\
\hline-100 & 45 & 1.70 & 1.544 & 620 & 663 & 652 & 133 & 40.92 \\
\hline-100 & 60 & 2.70 & 2.940 & 597 & 911 & 895 & 181 & 53.99 \\
\hline-100 & 70 & 3.30 & 3.800 & 680 & 1066 & 1055 & 204 & 65.18 \\
\hline-40 & 15 & 0.30 & 0.105 & 542 & 207 & 198 & 57 & 14.14 \\
\hline-40 & 30 & 1.00 & 0.530 & 660 & 459 & 453 & 124 & 27.64 \\
\hline-40 & 45 & 1.90 & 1.682 & 623 & 710 & 699 & 170 & 41.13 \\
\hline-40 & 60 & 2.70 & 2.960 & 610 & 987 & 972 & 219 & 54.20 \\
\hline-40 & 67 & 3.30 & 3.470 & 603 & 1057 & 1050 & 229 & 62.65 \\
\hline 0 & 15 & 0.30 & 0.112 & 600 & 245 & 241 & 93 & 14.17 \\
\hline 0 & 30 & 1.00 & 0.623 & 584 & 493 & 486 & 150 & 27.76 \\
\hline 0 & 45 & 1.90 & 1.660 & 532 & 740 & 731 & 197 & 41.24 \\
\hline 0 & 60 & 2.90 & 2.900 & 490 & 983 & 967 & 239 & 54.37 \\
\hline 0 & 66 & 3.30 & 3.260 & 523 & 1065 & 1050 & 250 & 61.07 \\
\hline+50 & 15 & 0.34 & 0.125 & 564 & 287 & 283 & 130 & 14.29 \\
\hline+50 & 30 & 1.10 & 0.669 & 540 & 534 & 527 & 183 & 27.91 \\
\hline+50 & 45 & 2.10 & 1.635 & 465 & 774 & 761 & 224 & 41.45 \\
\hline+50 & 60 & 3.00 & 2.840 & 474 & 1015 & 1002 & 257 & 54.65 \\
\hline+50 & 64 & 3.30 & 2.993 & 478 & 1060 & 1050 & 267 & 59.16 \\
\hline+70 & 15 & 0.35 & 0.132 & 445 & 297 & 292 & 141 & 14.37 \\
\hline+70 & 30 & 1.05 & 0.740 & 417 & 553 & 545 & 193 & 28.00 \\
\hline+70 & 45 & 2.10 & 1. 781 & 395 & 798 & 784 & 237 & 41.51 \\
\hline+70 & 57 & 2.80 & 2.584 & 445 & 980 & 968 & 275 & 53.07 \\
\hline
\end{tabular}

